\title{
Anurofauna da Floresta Estacional Semidecidual da Estação Ecológica dos Caetetus, Sudeste do Brasil
}

\author{
Ricardo Augusto Brassaloti, ${ }^{1,2}$, Denise de Cerqueira Rossa-Feres ${ }^{2}$ \& Jaime Bertoluci ${ }^{1,3}$ \\ ${ }^{1}$ Departamento de Ciências Biológicas, Escola Superior de Agricultura Luiz de Queiroz, \\ Universidade de São Paulo - USP, \\ Avenida Pádua Dias 11, CEP 13418-900 Piracicaba, SP, Brasil \\ ${ }^{2}$ Departamento de Zoologia e Botânica, Instituto de Biociências, Letras e Ciências Exatas, \\ Universidade Estadual Paulista - UNIP, \\ Rua Cristóvão Colombo 2265, CEP 15054-000 São José do Rio Preto, SP, Brasil \\ ${ }^{3}$ Autor para correspondência: Jaime Bertoluci,e-mail: bertoluc@esalq.usp.br
}

Brassaloti, R.A., ROSSA-FERES, D.C. \& Bertoluci, J. Anuran fauna of the Semideciduous Forest of the Estação Ecológica dos Caetetus, Southeastern Brazil. Biota Neotrop. 10(1): http://www.biotaneotropica.org.br/v10n1/en/abstract?inventory+bn01810012010.

\begin{abstract}
Semi-deciduous Forest is one of the most threatened and deforested vegetation types of Brazil due to its land conversion to agriculture in the beginning of the $20^{\text {th }}$ Century; its distribution is now reduced to less than $8 \%$ of its original extent. Studies about anuran taxocenosis associated to these forests are scarce, even when we consider the remaining areas of pristine forest. We present herein results from an amphibian survey at the Estação Ecológica dos Caetetus, a conservation unit with a singular preserved Semi-deciduous Forest from the Middle-West region of the State of São Paulo, located inside the priority areas for conservation on São Paulo State. We provided here data on species richness, composition, geographical distribution, and natural history notes for each taxa found in the area. We recorded 34 anuran species belonging to nine families, of which Hylidae and Leptodactylidae are the two most speciose families, with 14 and eight species respectively. The high species richness in the area, mainly in the family Hylidae, can be explained by both the high environmental heterogeneity of this remnant and its geographic location between Cerrado savannas and Atlantic rain forest areas. Its high species richness when compared with other localities of the same vegetation type, as well as the presence of forest dependent species in the families Centrolenidae, Hylodidae and Craugastoridae, indicate both the good conservation status and the regional importance of this forest remnant.
\end{abstract}

Keywords: anuran amphibians, natural history, inventory, Semi-deciduous Forest, Sao Paulo State.

BRASSALOTI, R.A., ROSSA-FERES, D.C. \& BERTOLUCI, J. Anurofauna da Floresta Estacional Semidecidual da Estação Ecológica dos Caetetus, sudeste do Brasil. Biota Neotrop., 10(1): http://www.biotaneotropica.org.br/v10n1/pt/abstract?inventory+bn01810012010.

Resumo: A Floresta Estacional Semidecidual é considerada uma das formações florestais mais ameaçadas e suprimidas pela expansão agrícola do início do século passado, com sua cobertura vegetal reduzida a menos de $8 \%$ da original. Estudos sobre taxocenoses de anfíbios anuros nessa formação florestal ainda são escassos, mesmo quando consideramos as poucas áreas de floresta primária que restaram. Apresentamos neste estudo os resultados de um levantamento de espécies de anfíbios anuros da Estação Ecológica dos Caetetus, uma unidade de conservação que abriga importante remanescente de Floresta Estacional Semidecidual na região Centro-oeste do estado de São Paulo, região considerada prioritária para conservação no estado. Foram registradas 34 espécies distribuídas em nove famílias, dentre as quais Hylidae e Leptodactylidae foram as que apresentaram as maiores riquezas, com 14 e oito espécies, respectivamente. A elevada riqueza de espécies da área, principalmente da família Hylidae, provavelmente está associada tanto à grande heterogeneidade ambiental dessa formação florestal como à sua localização em área de transição entre áreas de Cerrado e de Floresta Ombrófila. A alta riqueza de espécies, quando comparada à de outras áreas de mesma formação florestal, bem como a presença de representantes das famílias Centrolenidae, Craugastoridae e Hylodidae, que são dependentes de habitats florestais, atestam o bom estado de conservação e a importância regional desse remanescente florestal.

Palavras-chave: anfíbios anuros, história natural, inventário, Floresta Estacional Semidecidual, estado de São Paulo. 


\section{Introdução}

Parte do complexo de formações florestais da Floresta Atlântica e um dos mais ameaçados ecossistemas florestais brasileiros, a Floresta Estacional Semidecidual (FES) foi o tipo florestal mais rápida e extensamente devastado do estado de São Paulo (Ribeiro et al. 2009). A devastação dessa floresta ocorreu associada principalmente à expansão das fronteiras agrícolas no início do século XX, já que ocupavam os solos de maior fertilidade em regiões com relevo favorável à agricultura (Durigan et al. 2000). Dos fragmentos remanescentes, poucos têm área representativa, e apenas $6,8 \%$ do total da área dos remanescentes encontra-se preservada dentro de unidades de conservação (Ribeiro et al. 2009).

Grande parte dos estudos de anurofauna de florestas brasileiras foi desenvolvida em áreas preservadas da Amazônia (e.g. Gascon 1991, Gordo 2003, Lima et al. 2006), e da Floresta Ombrófila (e.g. Heyer et al. 1990, Guix et al. 1994, 2000, Bertoluci 1998, Bertoluci \& Rodrigues 2002a,b, Pombal Jr. \& Gordo 2004, Bertoluci et al. 2007, Condez et al. 2009), com o registro de grande riqueza de espécies. A menor riqueza de espécies de anuros em FES, quando comparada a taxocenoses de Floresta Ombrófila (e.g., Haddad \& Sazima 1992, Toledo et al. 2003, Bertoluci et al. 2007, Zina et al. 2007, Santos et al. 2009), possivelmente decorre do menor grau de heterogeneidade estrutural da paisagem e da menor diversidade de habitats e micro-habitats úmidos disponíveis às espécies (Haddad \& Prado 2005). Segundo Santos et al. (2009), a composição de espécies de anuros de áreas de FES, principalmente aquelas relacionadas ao Planalto Ocidental, é mais semelhante às registradas em áreas do Cerrado, do Pantanal e até mesmo do Pampa do que com as comunidades de Floresta Ombrófila. Esse padrão pode resultar tanto da sazonalidade climática daquelas áreas, que possuem estação seca bem definida, favorecendo a ocorrência de espécies generalistas que se reproduzem em corpos d'água de áreas abertas (Vasconcelos \& Rossa-Feres 2005, Santos et al. 2007), como da distância geográfica entre essas áreas e os centros de diversificação de anuros, como a Floresta Ombrófila (Carnaval et al. 2009, Santos et al. 2009).

A Estação Ecológica dos Caetetus é um dos últimos grandes remanescentes de FES do estado de São Paulo, juntamente com o Parque Estadual do Morro do Diabo e a Estação Ecológica de Jataí. Com o objetivo de contribuir para a diminuição de lacunas no conhecimento

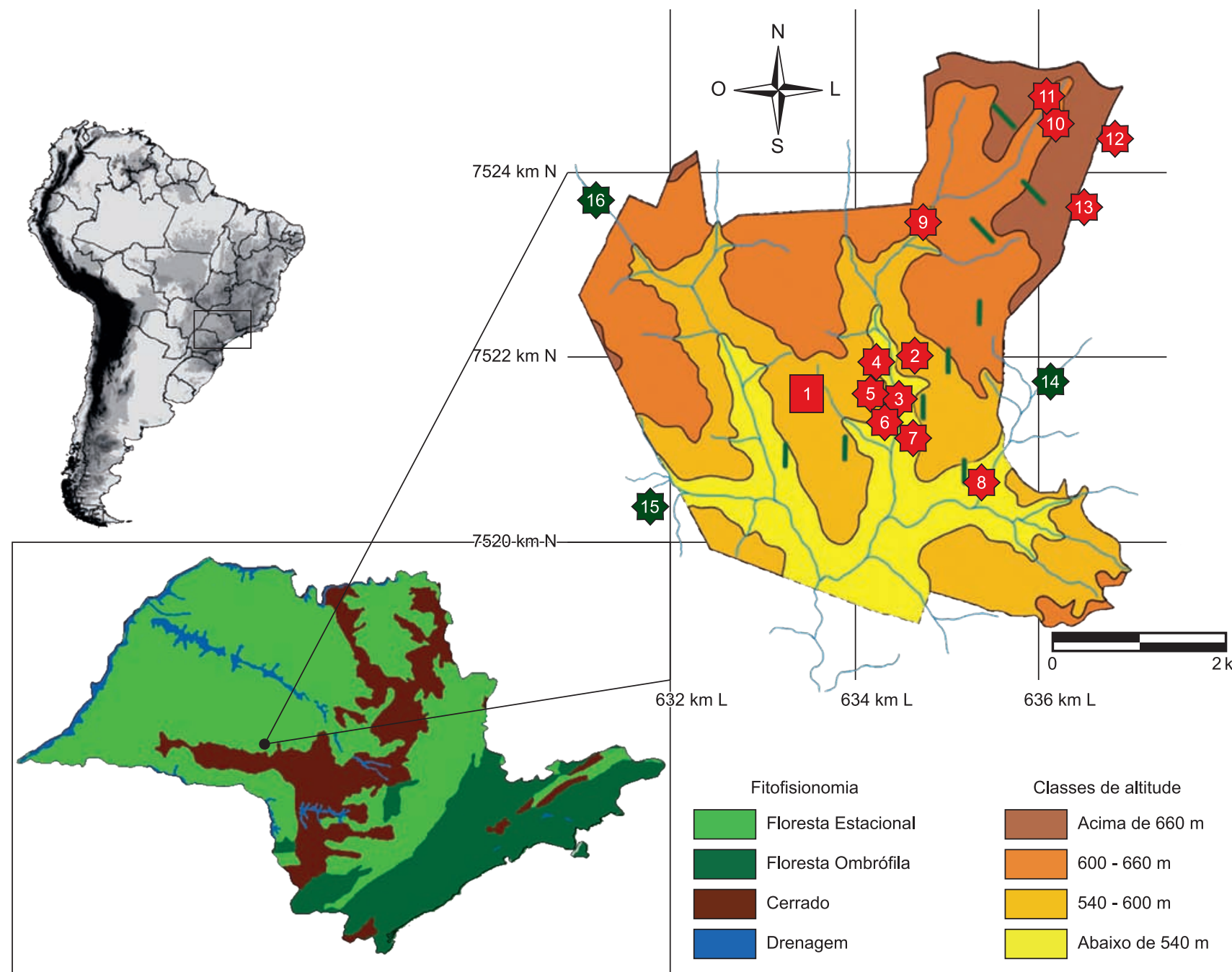

Figura 1. Localização geográfica da Estação Ecológica dos Caetetus, no estado de São Paulo, sudeste do Brasil (•), e das áreas amostradas pelos diferentes métodos na primeira (vermelho) e segunda (verde) etapas de amostragem. Legenda: Linhas- Armadilhas de Interceptação e Queda; 1- Área dos transectos; Corpos d'água (ver Apêndice 1 para as abreviaturas): 2- PT1; 3- CA; 4- PT2; 5- PT3; 6- BT; 7- BP; 8- AC; 9- CR; 10- PT4; 11- RP; 12- AT; 13- AP; 14- RB1; 15- PB; 16- RB2. Modificado de Tabanez et al. (2005).

Figure 1. Geographic location of the Caetetus Ecological Station in the state of São Paulo, southeastern Brazil $(\bullet)$, and of sampling sites from the first (red) and second (green) sampling campaigns.. Lines- Pitfall traps with drift fences; Numbers - Breeding sites; 1- Transect area; Numbers- Breeding sites (see Appendix 1 for abbreviations): 2- PT1; 3- CA; 4- PT2; 5- PT3; 6- BT; 7- BP; 8- AC; 9- CR; 10- PT4; 11- RP; 12- AT; 13- AP; 14- RB1; 15- PB; 16- RB2. Modified from Tabanez et al. (2005). 
da anurofauna associada a essa formação vegetal, apresentamos neste estudo a lista de espécies de anfíbios anuros da Estação Ecológica dos Caetetus, com informações sobre história natural e distribuição espacial das espécies. Essas são informações básicas, que podem ajudar na compreensão dos fatores que influenciam a composição da anurofauna associada a áreas de FES, com a possibilidade de serem utilizadas em estudos de meta-análise que auxiliem a definição de estratégias de conservação para o grupo.

\section{Material e Métodos}

\section{1. Área de estudo}

A Estação Ecológica dos Caetetus (EEC) possui uma área contínua de 2178,84 ha, com topografia ondulada e altitudes variando entre 500 e 680 m, e está situada entre os municípios de Gália e Alvilândia, estado de São Paulo (2224' 11' S e 49 42’05”'O) (Figura 1). O clima local, segundo a classificação de Köppen, é Cwa, mesotérmico de inverno seco, com temperatura média anual em torno de $21,5^{\circ} \mathrm{C}$, alcançando valores inferiores a $18{ }^{\circ} \mathrm{C}$ no inverno e superiores a $22^{\circ} \mathrm{C}$ no verão. A precipitação anual varia entre 1100 e $1700 \mathrm{~mm}$, concentrada nos meses de novembro a fevereiro, sendo julho e agosto os meses mais secos do ano, quando a precipitação não ultrapassa 30 mm (Tabanez et al. 2005,
Peel et al. 2007). A vegetação é classificada como Floresta Estacional Semidecidual do Planalto Ocidental do estado de São Paulo (Veloso et al. 1991), apresentando trechos em excelente estado de preservação. As áreas de FES do estado de São Paulo foram consideradas prioritárias para a criação de unidades de conservação devido à raridade de fragmentos de bom tamanho (Rodrigues et al. 2008). A área de estudo foi visitada antes do início das amostragens com a finalidade de reconhecimento e seleção de corpos d'água com diferentes fisionomias (represas, riachos, charcos e poças temporárias; Apêndice 1). A escolha dos locais para amostragem levou em consideração a distribuição destes pelas diferentes fisionomias florestais presentes na EEC, relacionadas com a estrutura da vegetação (primária, secundária e borda) e com a altitude (Figuras 1 e 2).

\section{Métodos de amostragem}

O levantamento na EEC foi realizado em duas etapas, com períodos, metodologias e locais de amostragem diferentes. A primeira etapa foi desenvolvida ao longo de 26 meses (setembro de 2005 a outubro de 2007) e a segunda, ao longo de uma estação chuvosa e parte da estação seca, totalizando nove meses de amostragem (outubro de 2008 a junho de 2009). Na primeira etapa foi realizado o levantamento da anurofauna de áreas de FES, principalmente
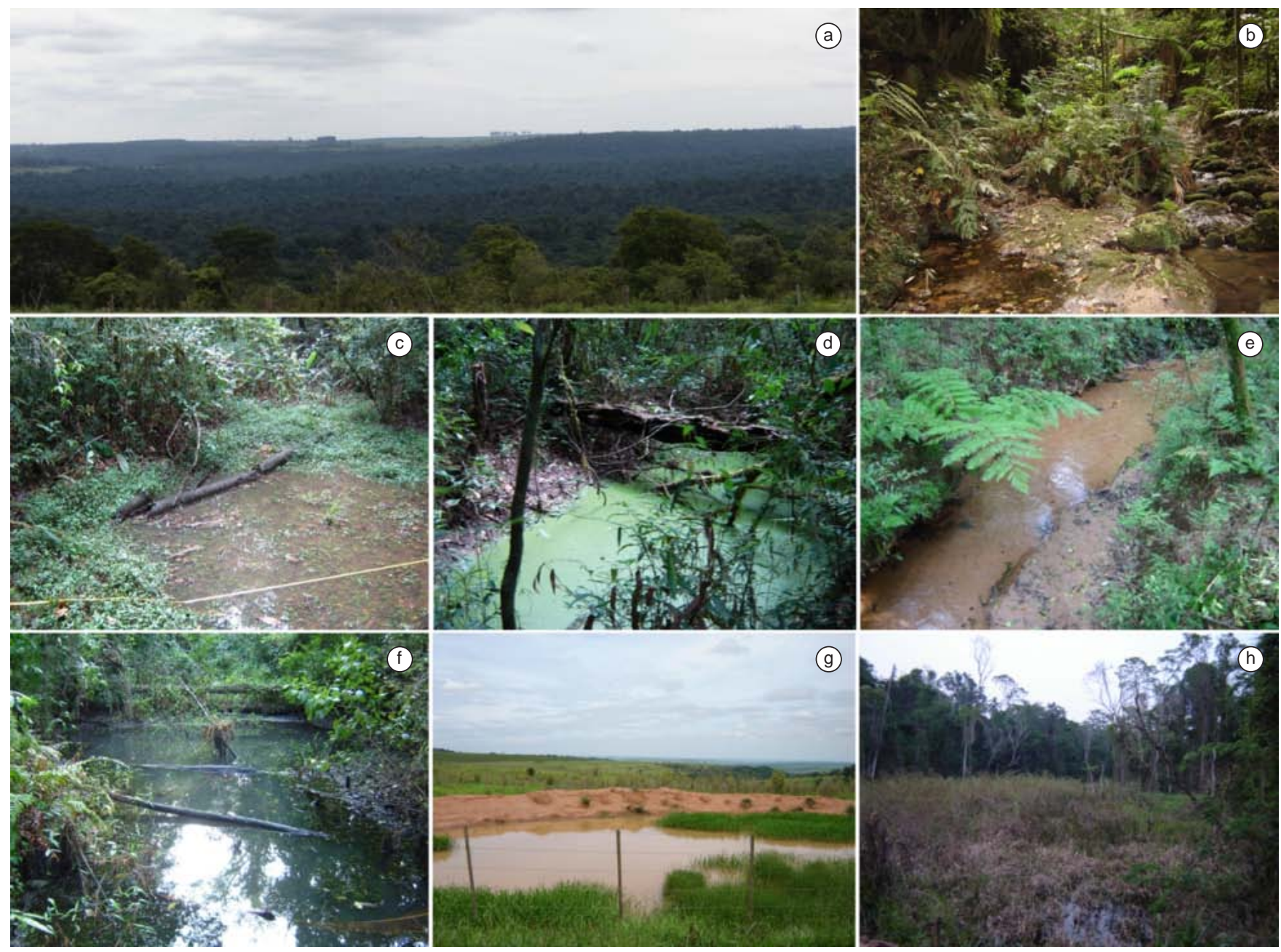

Figura 2. Alguns dos diferentes ambientes amostrados na Estação Ecológica dos Caetetus. a) Vista panorâmica de parte da EEC; Corpos d'água (ver Apêndice 1 para as abreviaturas): b) CR; c) PT1; d) PT3; e) CA; f) RP; g) AT; e h) AC. Fotos: R. A. Brassaloti.

Figure 2. Some of the sites sampled at Caetetus Ecological Station. a) Panoramic view of the EEC; Breeding sites (see Appendix 1 for abbreviations): b) CR; c) PT1; d) PT3; e) CA; f) RP; g) AT; and h) AC. Photos: R. A. Brassaloti. 
Brassaloti, R.A. et al.

Tabela 1. Espécies de anuros registradas na Estação Ecológica dos Caetetus entre setembro de 2005 e março de 2009: $1=$ primeira etapa de amostragem (setembro/2005 a outubro/2007), 2 = segunda etapa de amostragem (outubro/2008 a março/2009), $\mathrm{V}=$ Método de procura visual; $\mathrm{R}=$ Amostragem em locais de reprodução; Q = Armadilhas de Interceptação e Queda.

Table 1. Anuran species recorded in Caetetus Ecological Station between September 2005 and March 2009: $1=$ first sampling period (September 2005 to October 2007), 2 = second sampling period (October 2008 to March 2009), V = visual survey method; R = sampling at breeding sites; $Q=$ pitfall traps.

\begin{tabular}{|c|c|c|c|}
\hline Táxon & Método & $\begin{array}{c}\text { Etapa de } \\
\text { amostragem }\end{array}$ & $\begin{array}{c}\text { Hábitats de } \\
\text { ocorrência }\end{array}$ \\
\hline \multicolumn{4}{|l|}{ BUFONIDAE } \\
\hline Rhinella ornata & VRQ & 1,2 & Serapilheira e corpos d'água permanentes ou temporários, em área aberta ou na mata \\
\hline Rhinella schneideri & VRQ & 1,2 & Serapilheira, açudes e represas permanentes em área aberta ou área de clareira na mata \\
\hline \multicolumn{4}{|l|}{ CENTROLENIDAE } \\
\hline Vitreorana uranoscopa & $\mathrm{R}$ & 1 & Riachos com substrato arenoso dentro da mata \\
\hline \multicolumn{4}{|l|}{ CRAUGASTORIDAE } \\
\hline Haddadus binotatus & VQ & 1,2 & Serapilheira próximo a charcos temporários \\
\hline \multicolumn{4}{|l|}{ CYCLORAMPHIDAE } \\
\hline Odontophrynus americanus & VRQ & 1,2 & Serapilheira, charcos e açudes permanentes em área aberta na borda \\
\hline \multicolumn{4}{|l|}{ HYLIDAE } \\
\hline Dendropsophus elianeae & $\mathrm{R}$ & 2 & Charcos e poças temporários em área aberta na borda \\
\hline Dendropsophus minutus & $\mathrm{R}$ & 1,2 & Açudes em área aberta e charco e represa temporários dentro da mata \\
\hline Dendropsophus nanus & $\mathrm{R}$ & 1,2 & Charcos, poças e represas temporários ou permanentes dentro da mata e em clareiras \\
\hline Hypsiboas albopunctatus & $\mathrm{R}$ & 1,2 & Charcos e poças e represas permanentes em áreas de clareira no interior ou na borda da mata \\
\hline Hypsiboas caingua & $\mathrm{R}$ & 1,2 & Charcos e poças permanentes em áreas de clareira no interior ou na borda da mata \\
\hline Hypsiboas faber & $\mathrm{R}$ & 1,2 & Açudes e represas permanentes no interior da mata \\
\hline Hypsiboas lundii & $\mathrm{R}$ & 1,2 & Riachos e alagados adjacentes no interior da mata, em clareiras e na borda \\
\hline Itapotihyla langsdorffii & $\mathrm{R}$ & 1,2 & Charcos e poças temporários no interior da mata \\
\hline Phyllomedusa tetraploidea & $\mathrm{R}$ & 1,2 & Açudes, poças e represas temporários ou permanentes no interior da mata, clareiras e borda \\
\hline Scinax fuscomarginatus & $\mathrm{R}$ & 2 & Açudes, alagados e represas temporários ou permanentes na borda \\
\hline Scinax fuscovarius & $\mathrm{R}$ & 1,2 & Açudes e represas temporários ou permanentes em área aberta na borda \\
\hline Scinax hiemalis & $\mathrm{R}$ & 1 & Poças e charcos permanentes no interior e clareiras da mata \\
\hline Scinax perereca & VR & 1 & Serapilheira, charcos e poças temporários no interior da mata \\
\hline Scinax rizibilis & $\mathrm{R}$ & 1 & Charcos, poças e represas temporários ou permanentes no interior da mata \\
\hline \multicolumn{4}{|l|}{ HYLODIDAE } \\
\hline Crossodactylus cf. caramaschii & RQ & 1,2 & Cabeceira de riachos com matriz rochosa na mata \\
\hline \multicolumn{4}{|l|}{ LEIUPERIDAE } \\
\hline Eupemphix nattereri & VRQ & 1,2 & Serapilheira e açudes temporários ou permanentes em áreas abertas na borda \\
\hline Physalaemus cuvieri & VRQ & 1,2 & Serapilheira, açudes, poças e represas temporários ou permanentes na mata e na borda \\
\hline Physalaemus marmoratus & $\mathrm{R}$ & 2 & Poças temporárias em área aberta na borda \\
\hline Physalaemus cf. olfersii & VRQ & 1,2 & Serapilheira, poças e represas temporárias ou permanentes no interior da mata \\
\hline \multicolumn{4}{|l|}{ LEPTODACTYLIDAE } \\
\hline Leptodactylus chaquensis & $\mathrm{R}$ & 1 & Charcos e alagados temporários ou permanentes em áreas abertas \\
\hline Leptodactylus cf. furnarius & RQ & 2 & Poças e charcos temporários no interior e borda da mata \\
\hline Leptodactylus fuscus & VRQ & 1,2 & Serapilheira, açudes e alagados temporários ou permanentes em clareiras e na borda da mata \\
\hline Leptodactylus labyrinthicus & $\mathrm{R}$ & 1 & Açudes e represas temporários ou permanentes no interior e na borda da mata \\
\hline Leptodactylus cf. latrans & $\mathrm{R}$ & 1 & Açudes e alagados temporários ou permanentes em clareiras ou na borda da mata \\
\hline Leptodactylus mystaceus & VRQ & 1,2 & Serapilheira, charcos e poças temporárias no interior da mata \\
\hline Leptodactylus mystacinus & VRQ & 1,2 & Açudes, alagados, poças e represas temporários ou permanentes no interior ou na borda da mata \\
\hline Leptodactylus podicipinus & $\mathrm{R}$ & 2 & Açudes e alagados permanentes na borda da mata \\
\hline \multicolumn{4}{|l|}{ MICROHYLIDAE } \\
\hline Chiasmocleis albopunctata & $\mathrm{R}$ & 2 & Açudes e poças temporários na borda da mata \\
\hline Elachistocleis cf. ovalis & $\mathrm{R}$ & 1 & Açudes e poças temporários ou permanentes na borda da mata \\
\hline
\end{tabular}


dentro da EEC, sendo empregadas duas metodologias visando o registro de espécies com diferentes hábitos. A procura visual (Crump \& Scott Jr. 1994) foi aplicada durante o período diurno em todos os micro-ambientes visualmente acessíveis e na serapilheira, ao longo de 16 transectos de um metro de largura e $320 \mathrm{~m}$ de comprimento (total de $5.120 \mathrm{~m}$ ). Esse método foi aplicado mensalmente (outubro de 2005 a setembro de 2006) por dois dias consecutivos, totalizando um esforço amostral de 240 horas/pessoa, desenvolvido por dois pesquisadores simultaneamente. A amostragem em locais de reprodução (Scott \& Woodward 1994) foi realizada durante duas visitas noturnas consecutivas por mês (setembro de 2005 a outubro de 2007), no horário de maior atividade reprodutiva das espécies (19:00 - 00:00 horas), ao longo de todo o período da primeira etapa, totalizando 26 meses de amostragem nos 12 corpos d'água previamente selecionados, com um total de 260 horas/pessoa de esforço amostral, desenvolvido por dois pesquisadores simultaneamente.

Na segunda etapa do levantamento, também foram empregadas duas metodologias de amostragem. A amostragem em locais de reprodução foi feita em três corpos d'água localizados na borda da floresta da EEC (área de pastagem no entorno), durante uma noite por mês ao longo de nove meses de amostragem, totalizando um esforço de 54 horas/pessoa. Concomitantemente, foram usadas armadilhas de interceptação e queda (Corn 1994, Cechin \& Martins 2000) dispostas em nove unidades amostrais distribuídas ao longo de gradientes altitudinal e de estrutura da vegetação. Cada unidade amostral consistiu de uma linha composta por quatro baldes de $100 \mathrm{~L}$ enterrados até a borda e equidistantes $16 \mathrm{~m}$, transpassados por cerca direcionadora constituída de lona plástica com 50 m de extensão e $1 \mathrm{~m}$ de altura presa a estacas de madeira, com a borda inferior enterrada
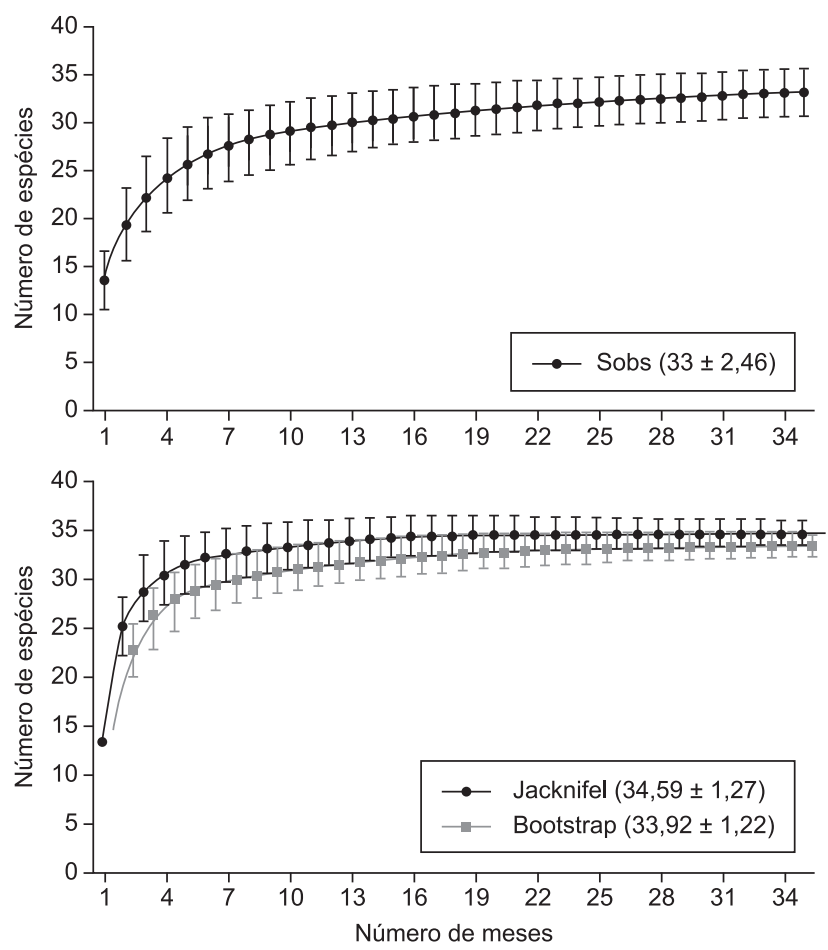

Figura 3. Curva de acumulação de espécies (acima) e estimadores de riqueza (abaixo) Jacknife I (preto) e Bootstrap (cinza), confeccionadas a partir de 1.000 aleatorizações e com suas respectivas barras de desvio padrão.

Figure 3. Species accumulation curve (above) and richness estimators (below) Jacknife I (black marks) and Bootstrap (gray marks) built from 1.000 randomizations and with its respective standard deviations bars. a $15 \mathrm{~cm}$ no solo, passando pelo centro dos baldes. As armadilhas permaneceram abertas durante nove dias consecutivos, com checagem a cada 48 horas em cada um dos nove meses de amostragem (81 dias), totalizando um esforço amostral de 2.916 noites-balde para o conjunto das armadilhas.

Exemplares-testemunho estão depositados na Coleção Herpetológica do Laboratório de Zoologia de Vertebrados da ESALQUSP (VESALQ) e na Coleção Científica de Anfíbios do Departamento de Zoologia e Botânica da UNESP de São José do Rio Preto (DZSJRP) (Apêndice 2). Para isso, alguns indivíduos de cada espécie foram coletados (licenças IBAMA 430/05 e 18204-1), anestesiados até a morte em atmosfera saturada de $\mathrm{CO}_{2}$ (de acordo com a resolução $\mathrm{N}^{\circ}$. 714 de 20 de junho de 2002 da CFMV), fixados em formalina $10 \%$ e conservados em solução de álcool etílico a $70 \%$.

\section{Análise dos dados}

A eficiência da amostragem foi avaliada por aleatorização da curva do coletor (e.g. Gotelli \& Colwell 2001, Colwell et al. 2004), a partir da matriz de dados de presença mensal das espécies registradas pelo método de amostragem em locais de reprodução (único método empregado nas duas fases), com 10.000 aleatorizações e reposição de amostras. A riqueza de espécies da área foi estimada por modelos de extrapolação da curva de acumulação de espécies pelos métodos Bootstrap e Jacknife I (Santos 2003), mais indicados para dados de presença e ausência, sendo as curvas escalonadas em função do número de amostras, em que cada amostra corresponde a uma viagem mensal. Ambas as análises foram efetuadas no Programa EstimateS, versão 7.5.2 (Colwell 2005).

\section{Resultados e Discussão}

A taxocenose da área é representada por um total de 34 espécies distribuídas em nove famílias e 15 gêneros (Frost 2009), sendo a família Hylidae a mais rica (14 espécies). As 20 espécies restantes estão distribuídas em oito famílias: Leptodactylidae (8 espécies), Leiuperidae (4), Bufonidae (2), Microhylidae (2), Centrolenidae (1), Craugastoridae (1), Cycloramphidae (1) e Hylodidae (1) (Tabela 1). Todas as espécies capturadas nas armadilhas de interceptação e queda também foram registradas com os outros métodos de amostragem. Com exceção de Haddadus binotatus, todas as demais espécies foram registradas por busca em locais de reprodução. Assim, apesar de o esforço de captura por armadilhas de interceptação e queda ter sido consideravelmente maior que o dos outros métodos de amostragem em um mesmo período de tempo, a procura noturna em corpos d'água parece ser mais eficiente para registrar a grande maioria das espécies, pelo menos para áreas de FES, onde a maioria das espécies se congrega em corpos d'água durante o período reprodutivo, sendo este o método adequado quando apenas um método puder ser empregado para a realização de inventários.

A curva de acumulação de espécies não se estabilizou, entretanto o incremento de espécies diminuiu a partir da vigésima quarta amostragem, quando foram necessários 11 meses de amostragem para acrescentar uma espécie à curva (Figura 3). A riqueza estimada acrescenta apenas uma espécie (Jacknife I: 34,59 \pm 1,27; Bootstrap: $33,92 \pm 1,22)$ ao total de 33 espécies registradas pelo método de amostragem em locais de reprodução (Tabela 1). O comportamento da curva e os valores previstos pelos estimadores de riqueza para a área sugerem que o esforço de amostragem foi suficiente para registrar a grande maioria das espécies nos ambientes de interior e da borda da EEC, com previsão de registro de, no máximo, duas espécies adicionais (Figura 3).

Abaixo apresentamos a lista de espécies da área com comentários sobre taxonomia, distribuição geográfica e informações 


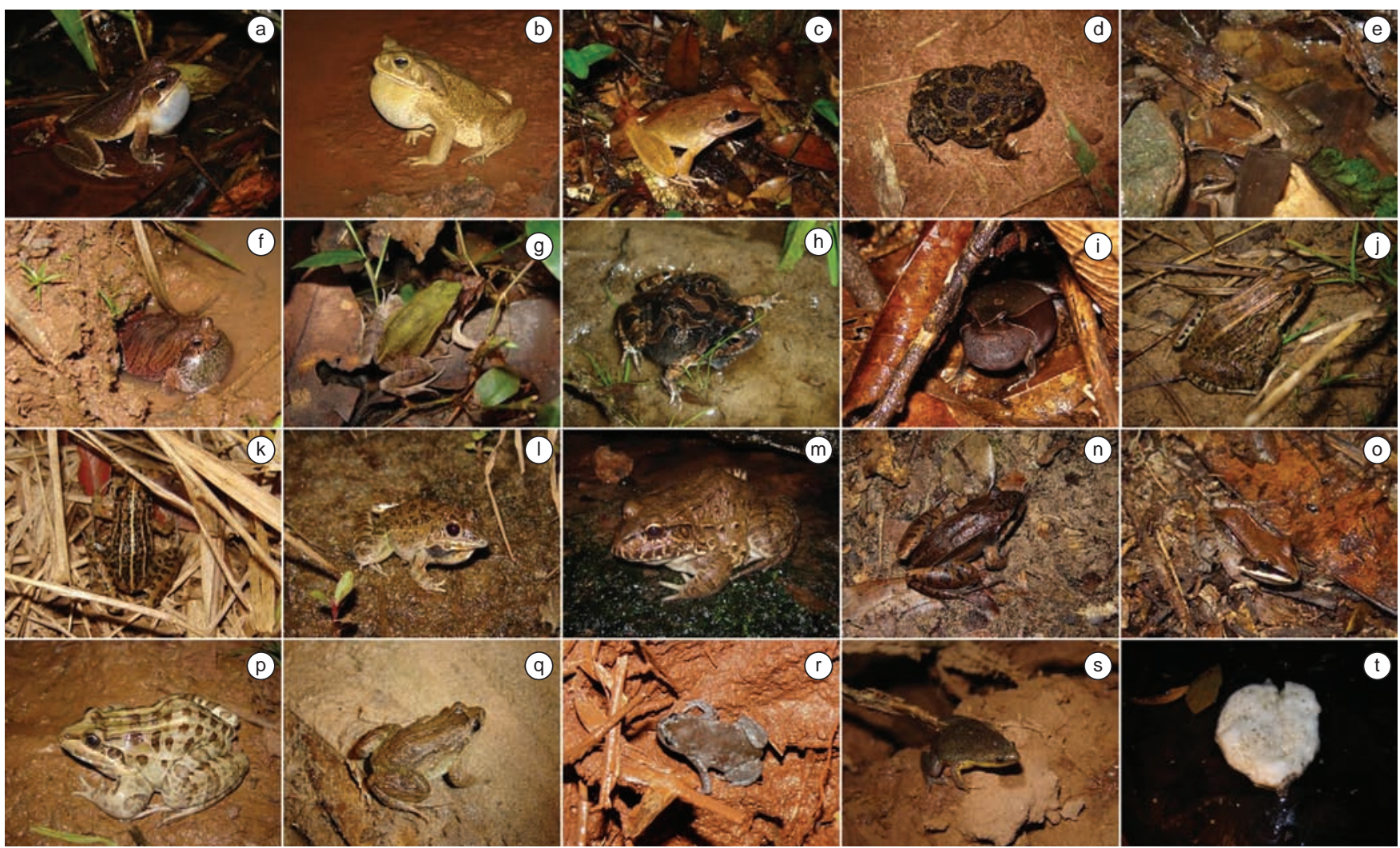

Figura 4. Espécies de anfíbios anuros de hábito terrestre encontrados na EEC entre setembro de 2005 e fevereiro de 2009. a) Rhinella ornata ${ }^{\lambda}$; b) R. schneideri 予; c) Haddadus binotatus; d) Odontophrynus americanus ô; e) Casal de Crossodactylus cf. caramaschii; f) Eupemphix nattereri $\hat{O}^{2}$; g) Amplexo de Physalaemus

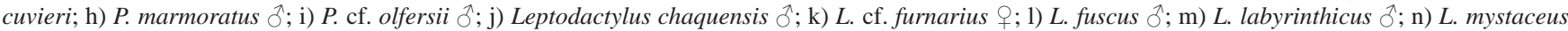

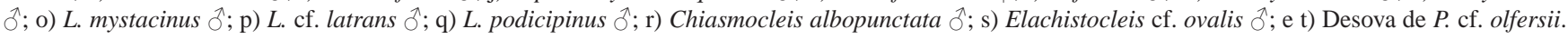
Fotos: R.A. Brassaloti.

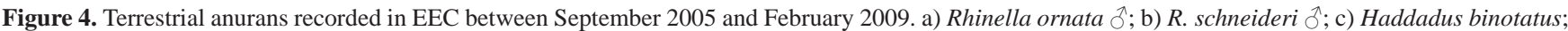

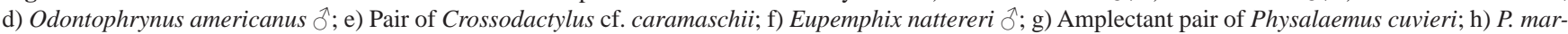

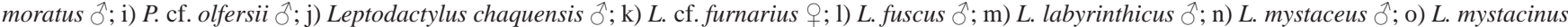

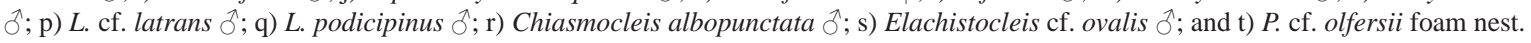

sobre história natural das espécies na EEC. Essa lista acrescenta o registro de dez espécies aos dados apresentados por Bertoluci et al. (2007) (Vitreorana uranoscopa, Dendropsophus elianeae, Scinax fuscomarginatus, S. hiemalis, Physalaemus marmoratus, Leptodactylus furnarius, L. chaquensis, L. cf. latrans, L. podicipinus e Chiasmocleis albopunctata) e altera a identidade de duas espécies (Scinax x-signatus para S. perereca e Hylodes sp. para Crossodactylus caramaschii).

\section{FAMÍLIA BUFONIDAE}

\section{Rhinella ornata (Spix, 1824) - Figura 4a}

Espécie abundante em áreas florestais, encontra-se associada a áreas do domínio da Floresta Atlântica no sudeste brasileiro (Floresta Ombrófila Densa e FES) e partes do cerrado paulista (Brasileiro et al. 2005), em altitudes que vão do nível do mar, na faixa litorânea, até pouco acima dos 1000 m, na Serra do Mar (Dixo \& Verdade 2006). Ocorre desde o sul do Espírito Santo, por todo o Rio de Janeiro e São Paulo até o extremo norte do Paraná e possivelmente nordeste da Argentina (Baldissera Jr. et al. 2004, Frost 2009). Apresenta certa plasticidade quanto à ocorrência em áreas degradadas ou de antiga fragmentação florestal (IUCN 2009), sendo a atividade reprodutiva observada em riachos com pouca correnteza ou ambientes lênticos, naturais ou artificiais, de áreas abertas, da borda da mata e do interior da floresta (Bertoluci \& Rodrigues 2002a), fato também constatado na EEC. Segundo Guix et al. (1998) os jovens apresentam atividade diurna, sendo os adultos crepusculares ou noturnos, porém no presente estudo foram encontrados adultos deslocando-se na serapilheira $(\mathrm{n}=12)$, principalmente no período da manhã ou após chuvas fortes durante o dia. Sua estação reprodutiva está associada tanto à estação chuvosa como à estação seca (Bertoluci 1998, Bertoluci \& Rodrigues 2002b, Zina et al. 2007, Narvaes et al. 2009), podendo ser considerada explosiva (Bertoluci 1998) e com dois picos anuais de vocalização (Bertoluci \& Rodrigues 2002b).

\section{Rhinella schneideri (Werner, 1894) - Figura 4b}

Amplamente distribuída por ambientes tipicamente nãoflorestais, é encontrada em vários biomas, incluindo o Chaco-Pantanal, Cerrado e Caatinga; porém também ocorre em regiões da Floresta Atlântica, principalmente em FES, ocupando desde pequenos fragmentos até grandes áreas florestais, como no caso da EEC, embora comumente ocorra em agroecossistemas e áreas urbanizadas (IUCN 2009). Distribui-se por todas as regiões brasileiras, exceto na região Norte, além do Paraguai, partes da Argentina, Bolívia e Uruguai (Frost 2009). A atividade reprodutiva dessa espécie ocorre em açudes e represas perenes ou com grande resistência ao dessecamento (Toledo et al. 2003). A espécie possui reprodução explosiva, freqüentemente ocorrendo no fim da estação seca e fria e início da estação chuvosa e quente (Toledo 

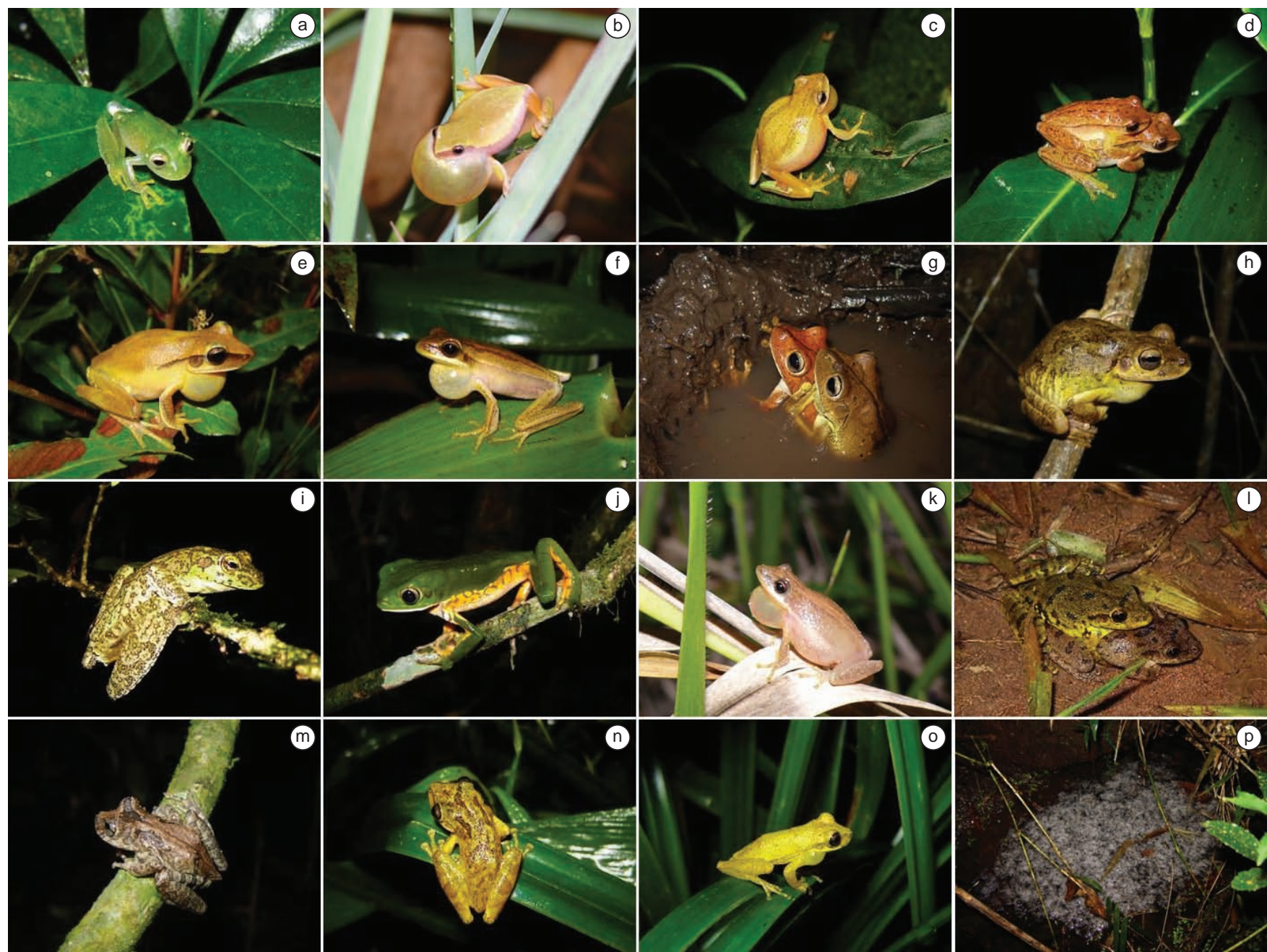

Figura 5. Espécies de anfíbios anuros de hábito arborícola encontradas na EEC entre setembro de 2005 e fevereiro de 2009. a) Vitreorana uranoscopa ${ }^{7}$; b)

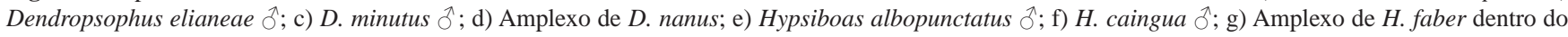

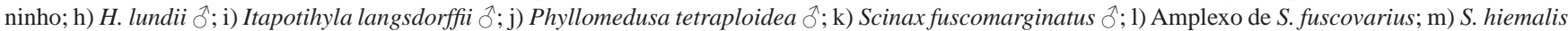

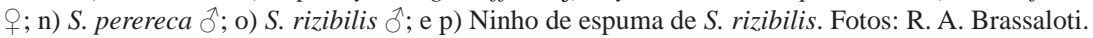

Figure 5. Arboreal anurans found in EEC between September 2005 and February 2009. a) Vitreorana uranoscopa 万人; b) Dendropsophus elianeae ô; c) D. minutus ; d) Amplectant pair of D. nanus; e) Hypsiboas albopunctatus o ; f) H. caingua O ; g) Amplectant pair of H. faber inside the nest; h) H. lundii 3 ; i) Itapotihyla

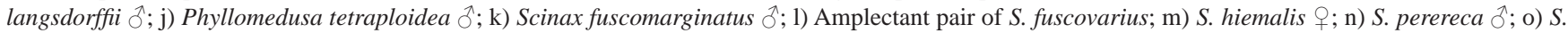

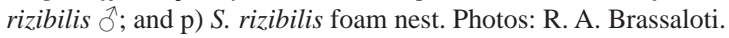

et al. 2003, Brasileiro et al. 2005, Vasconcelos \& Rossa-Feres 2005, Santos et al. 2007).

\section{FAMÍLIA CENTROLENIDAE}

\section{Vitreorana uranoscopa (Müller, 1924) - Figura 5a}

Única espécie registrada da família Centrolenidae, recentemente alocada no gênero Vitreorana juntamente com outras espécies do sul e sudeste brasileiro (Guayasamin et al. 2009), tem sua ocorrência fortemente associada a florestas bem-preservadas do domínio da Floresta Atlântica (Floresta Ombrófila Densa e Mista e FES) do sudeste e sul do Brasil, da faixa litorânea até acima dos 1200 m (IUCN 2009, Carvalho-e-Silva et al. 2008). Sua distribuição abrange os estados do Espírito Santo, ao norte, até o Rio Grande do Sul, na zona costeira, estendendo-se a oeste pelo sudeste e sul de Minas Gerais e centro de São Paulo, e partes adjacentes no Paraguai e Argentina (Heyer 1985, Frost 2009). Reproduz-se em riachos de substrato arenoso e matriz rochosa, depositando uma massa gelatinosa com os ovos na superfície de folhas na margem
(Haddad \& Prado 2005). Apresenta atividade reprodutiva associada ao período chuvoso, sendo considerada como oportunista explosiva, com grandes picos reprodutivos após chuvas torrenciais no verão (Heyer 1985, Heyer et al. 1990, Canelas \& Bertoluci 2007). Na EEC foi encontrada apenas de dezembro de 2006 a fevereiro de 2007, com picos de atividade reprodutiva (8 a 9 machos vocalizando) em noites após chuva intensa (mais de $30 \mathrm{~mm}$ ). A presença dessa espécie na EEC evidencia o bom estado de conservação da área, dada a conhecida exigência do grupo quanto às características do hábitat (e.g. Heyer 1985, Cisneros-Heredia \& McDiarmid 2007), sendo este registro o mais a oeste da sua distribuição no estado de São Paulo (Botucatu/SP) (Jim 1980).

\section{FAMÍLIA CRAUGASTORIDAE}

\section{Haddadus binotatus (Spix, 1824) - Figura 4c}

O único representante encontrado da recém-criada família Craugastoridae (Hedges et al. 2008) apresenta distribuição restrita à faixa de domínio da Floresta Atlântica que se estende do sul 
da Bahia até o norte do Rio Grande do Sul (IUCN 2009, Frost 2009), tendo na EEC seu limite mais a oeste no estado de São Paulo (Botucatu/SP) (Jim 1980). Comum somente no interior ou nas bordas de floresta dentro da sua área de ocorrência, pode ser encontrada em atividade durante o dia, o crepúsculo e a noite na serapilheira (Pombal Jr. \& Gordo 2004, Dixo \& Verdade 2006), onde os ovos são depositados e se desenvolvem diretamente em miniaturas dos adultos (Heyer et al. 1990). Com exceção de fêmeas ovígeras, não foi constatada atividade reprodutiva (machos vocalizando, casais em amplexo e desova) para essa espécie na EEC, porém foram observados 10 indivíduos jovens deslocando-se pela serapilheira nos meses de fevereiro e março, sugerindo atividade reprodutiva associada ao período chuvoso. Os indivíduos foram encontrados somente no interior da mata, reforçando sua associação com áreas bem preservadas.

\section{FAMÍLIA CYCLORAMPHIDAE}

\section{Odontophrynus americanus (Duméril \& Bibron, 1841) - Figura 4d}

Juntamente com outras três espécies $(O$. lavillai, $O$. cordobae e O. maisuma), compõe o complexo O. americanus (Rosset 2008), para o qual é relatada a presença de populações tetraplóides, triplóides e diplóides, muitas delas consideradas como espécies crípticas registradas para diferentes localidades dentro de sua área de ocorrência (e.g. Rosset et al. 2006). Esse fato dificulta a delimitação de sua distribuição geográfica, que se estende pelo centro-oeste e sudeste brasileiro até Minas Gerais, passando pelo Paraguai, Uruguai até a região central da Argentina (Frost 2009), ocupando desde áreas de cerrado e sistema Chaco-Pantanal, até a Floresta Ombrófila (Bertoluci 1998, IUCN 2009). Por possuir hábito semi-fossório, é encontrada com maior frequiência antes ou durante seu período de reprodução, geralmente associado ao fim da estação seca e fria e início da estação quente e chuvosa (Bertoluci 1998, Conte \& Machado 2005). A reprodução ocorre em ambientes lênticos de áreas abertas (Bertoluci \& Rodrigues 2002a). Não foram observadas agregações reprodutivas nos pontos amostrados, porém em apenas uma noite de fortes chuvas em fevereiro de 2006 foram observados 15 sub-adultos deslocando-se na serapilheira no interior da EEC.

\section{FAMÍLIA HYLIDAE}

\section{Dendropsophus elianeae (Napoli \& Caramaschi, 2000) - Figura 5b}

Pertencente ao grupo D. microcephalus (Faivovich et al. 2005), essa espécie está associada a fitofisionomias abertas, especialmente do Cerrado do centro e sudeste do Brasil nos estados de Goiás, Mato Grosso, Mato Grosso do Sul e São Paulo e também no centro-leste do Paraguai (Napoli \& Caramaschi 2000, Frost 2009). Machos de D. elianeae vocalizam na parte superior de vegetação herbácea, predominantemente gramíneas, empoleirados entre 0,5 a $1 \mathrm{~m}$ de altura, nas margens de corpos d'água lênticos permanentes ou temporários, mas com maior abundância nos corpos d'água permanentes (Jim 1980, Vasconcelos \& Rossa-Feres 2005). Os machos vocalizam ao longo da estação chuvosa (Jim 1980), com pico de abundância em plena estação (novembro a janeiro) (Vasconcelos \& Rossa-Feres 2005). Essa espécie foi registrada apenas em açudes e represas na borda da EEC, somente na segunda etapa de amostragem, reforçando sua associação dessa espécie com ambientes de áreas abertas.

\section{Dendropsophus minutus (Peters, 1872) - Figura 5c}

Uma das espécies de hilídeos com maior distribuição na América do Sul, pertence ao grupo de mesmo nome, ao lado de outras três espécies reconhecidas (D. delarivai, D. limai e D. xapuriensis) (Faivovich et al. 2005). Por vezes considerada como um complexo de espécies crípticas (Hawkins et al. 2007), é muito comum em todos os biomas brasileiros (IUCN 2009), sendo registrada a leste dos Andes em altitudes abaixo dos 2.000 m, desde a Colômbia, Venezuela, Guianas, passando ao sul pelo Equador, Peru, Bolívia, Paraguai, nordeste da Argentina e Uruguai (Frost 2009). Apresenta um padrão contínuo de reprodução em áreas com baixa variação sazonal, como na Floresta Ombrófila (Bertoluci 1998, Bertoluci \& Rodrigues 2002a), sendo que para áreas com marcado período de estiagem as agregações reprodutivas estão mais associadas à estação quente e chuvosa (Brasileiro et al. 2005, Vasconcelos \& Rossa-Feres 2005, Kopp \& Eterovick 2006, Canelas \& Bertoluci 2007, Santos et al. 2007), como foi o caso na EEC, tendo sido registradas grandes agregações somente em ambientes da borda da floresta.

\section{Dendropsophus nanus (Boulenger, 1889) - Figura 5d}

Assim como D. elianeae, esse pequeno hilídeo pertence ao grupo D. microcephalus (Faivovich et al. 2005), ocorrendo em quase todos os biomas brasileiros, excetuando-se a zona costeira, da bacia Amazônica ao leste da Bolívia, Paraguai, norte do Uruguai até a bacia do Prata, na Argentina (Frost 2009). Possivelmente corresponde a um complexo de espécies crípticas (IUCN 2009). Os machos vocalizam em corpos d'agua lênticos de áreas abertas, da borda da mata e do interior da floresta, permanentes ou temporários (Bertoluci \& Rodrigues 2002a), empoleirados em gramíneas ou sobre a vegetação arbustiva marginal ou sobre a água (Rossa-Feres \& Jim 2001, Bertoluci \& Rodrigues 2002a, Toledo et al. 2003). Tem seu período de reprodução associado à estação quente e chuvosa, apresentando grandes agregações reprodutivas (Bertoluci 1998, Bertoluci \& Rodrigues 2002b, Toledo et al. 2003, Vasconcelos \& Rossa-Feres 2005, Canelas \& Bertoluci 2007, Santos et al. 2007), que ocorreram tanto no interior como na borda da floresta e em clareiras na EEC.

\section{Hypsiboas albopunctatus (Spix, 1824) - Figura 5e}

Tem sua ocorrência fortemente relacionada com áreas de cerrado e outras formações vegetais abertas, além de áreas com grandes alterações antrópicas, abaixo dos 2.000 m (IUCN 2009). Sua distribuição geográfica inclui o estado de Rondônia ao norte até o Rio Grande do Sul, passando pelo centro-oeste, sudeste e sul do Brasil, além da Bahia no seu limite leste, com exceção da faixa litorânea brasileira, além do leste da Bolívia e do Paraguai, nordeste da Argentina e norte do Uruguai (IUCN 2009, Frost 2009). A reprodução ocorre em grandes agregações, principalmente, ao longo da estação quente e chuvosa, com machos vocalizando em torno de várzeas e corpos d'água lênticos temporários ou permanentes (Bertoluci \& Rodrigues 2002a, Toledo et al. 2003, Canelas \& Bertoluci 2007, Santos et al. 2007). Na EEC foi encontrada apenas em ambientes aquáticos no entorno ou em clareiras na mata, apresentando maiores agregações reprodutivas em brejos ou açudes permanentes.

\section{Hypsiboas caingua (Carrizo, 1991 “1990”) - Figura 5f}

Essa espécie tem distribuição disjunta, com uma população relacionada às províncias de Misiones e Corrientes, no nordeste da Argentina, e áreas adjacentes do sudeste do Paraguai, e outras populações isoladas, nos estados de São Paulo e Rio Grande do Sul, no Brasil (Frost 2009). É associada a ambientes de formação vegetal aberta próximo a fragmentos de mata, reproduzindo-se em corpos de água corrente ou com constante troca, sendo pouco frequente em corpos de água parada (Jim 1980). Quando ocupam corpos de água corrente, sempre são observadas nas áreas de remanso ou de menor correnteza e maior quantidade de vegetação, sendo que os machos vocalizam em gramíneas de 
talo ereto ou sobre a vegetação herbácea, empoleirados a até $1 \mathrm{~m}$ de altura, mas não são observados vocalizando sobre o solo ou na água (Jim 1980). Na região sudeste do Brasil, a maior atividade de vocalização ocorre em março (Jim 1980), mas na EEC apresentou agregações reprodutivas durante todo o ano, apenas com uma diminuição na abundância de machos em atividade no inverno, em noites com temperatura inferior a $15{ }^{\circ} \mathrm{C}$.

6. Hypsiboas faber (Wied-Neuwied, 1821) - Figura 5g

Essa espécie, pertencente ao grupo H. boans (Faivovich et al. 2005), apresenta ligação íntima com áreas do domínio da Floresta Atlântica em todas as suas formações (Floresta Ombrófila Mista e Densa e FES), do sul da Bahia ao Rio Grande do Sul, sudeste do Paraguai e na província de Misiones, na Argentina (Frost 2009), com relativa tolerância a modificações no habitat (IUCN 2009). Sua atividade reprodutiva quase sempre compreende toda a estação chuvosa (Bertoluci 1998, Bertoluci \& Rodrigues 2002a, Conte \& Machado 2005, Canelas \& Bertoluci 2007), sendo comum a presença de agregações de machos vocalizando a partir do chão ao lado das cavidades (bacias) que escavam nas margens alagáveis dos corpos d'água. Os ovos são depositados nas bacias, onde os girinos eclodem e se desenvolvem até seus estágios iniciais, passando para o corpo d'água principal quando os ninhos são inundados pela chuva. Machos rivais podem apresentar comportamento agonístico, defendendo seus ninhos em lutas que envolvem o uso de seus pré-polex, que podem impor severos danos ao adversário (Martins \& Haddad 1988, Bertoluci 1991). Na EEC esteve quase sempre associada a açudes e represas, com maiores agregações reprodutivas em áreas de clareiras ou na borda da mata.

\section{Hypsiboas lundii (Burmeister, 1856) - Figura 5h}

Inserida no grupo H. boans (Faivovich et al. 2005) e relacionada a áreas de Floresta Atlântica e Cerrados, possui ocorrência quase sempre associada a áreas florestais, seja em matas de galeria ou em fragmentos (FES ou Cerrado arbóreo) que tenham ou que estejam próximo a riachos (Toledo et al. 2003, Brasileiro et al. 2005). Distribui-se em áreas até $1.100 \mathrm{~m}$ de altitude, ao longo dos estados de Goiás, Minas Gerais e São Paulo e no Distrito Federal (IUCN 2009, Frost 2009). Assim como as outras espécies do grupo, apresenta modo reprodutivo especializado, construindo seus ninhos nas margens de riachos (Faivovich et al. 2005, Araujo et al. 2009). Reproduz-se no início da estação chuvosa, mas machos podem ser encontrados vocalizando empoleirados em altura superior a $5 \mathrm{~m}$ durante toda a estação chuvosa e esporadicamente na estação seca (Toledo et al. 2003, Brasileiro et al. 2005). Na EEC os machos formaram pequenas agregações reprodutivas em riachos e/ou poças e represas adjacentes a estes, inseridos no contínuo florestal ou em áreas de borda com riachos e vegetação arbórea estruturada.

\section{Itapotihyla langsdorffii (Duméril \& Bibron, 1841) - Figura 5i}

Essa espécie tem ampla distribuição pela região do domínio da Floresta Atlântica, estando fortemente associada aos remanescentes florestais bem conservados desse bioma em suas diversas formações florestais, ocorrendo desde o estado de Sergipe ao norte até o Rio Grande do Sul, alcançando áreas do nordeste da Argentina e leste do Paraguai em sua porção mais ocidental (Arzabe \& Loebmann 2006, Frost 2009). Apresenta atividade reprodutiva associada aos períodos mais quentes e chuvosos do ano (dezembro e janeiro), quando os machos vocalizam sobre a vegetação arbórea-arbustiva associada a poças temporárias do interior de mata, apenas por alguns dias (Toledo et al. 2003,
IUCN 2009). Na EEC foi encontrada em grandes agregações reprodutivas (10 machos vocalizando) apenas em dezembro de 2005 em um corpo d'água temporário no interior da mata.

\section{Phyllomedusa tetraploidea Pombal Jr. \& Haddad, 1992 - Figura 5j}

Considerada dentro do grupo P. burmeisteri (Faivovich et al. 2005), derivou por tetraploidia de P. distincta (Pombal Jr. Jr. \& Haddad 1992), com a qual é registrado caso de hibridação natural em localidade onde ocorrem em simpatria (Haddad et al. 1994). Essa espécie apresenta ocorrência associada aos remanescentes florestais do interior dos estados de São Paulo e Paraná, em Misiones, na Argentina, e sudeste do Paraguai, em altitudes que variam de 400 a 1.000 m (Frost 2009, IUCN 2009, Ribeiro Jr. \& Bertoluci 2009). Sua desova é depositada em folhas pendentes sobre corpos d'água; ao eclodirem, os girinos caem na poça e desenvolvem-se na água (Pombal Jr. \& Haddad 1992). A reprodução ocorre ao longo da estação quente e chuvosa, com grandes agregações reprodutivas (Bernarde \& Anjos 1999, Bernarde \& Machado 2000, Araujo et al. 2009). Na EEC foram observados maiores picos de abundância nas agregações reprodutivas nos meses de janeiro e fevereiro, além de comportamento agonístico entre machos por amplexo em uma mesma fêmea $(n=3)$ e amplexos e desova sob vegetação rasteira (gramíneas) $(\mathrm{n}=8)$ em açude na borda da mata.

\section{Scinax fuscomarginatus (A. Lutz, 1925) - Figura 5k}

Apresenta ampla distribuição geográfica, que abrange diversos biomas brasileiros, com exceção dos costeiros, quase sempre ocupando formações abertas (e.g. cerrado e caatinga) (IUCN 2009). Distribui-se pelo interior do Brasil nos estados do Piauí e Ceará a norte, margeando o limite amazônico até Santa Catarina, leste da Bolívia, Paraguai e nordeste da Argentina (Frost 2009). Durante a estação quente e chuvosa, os machos utilizam lagoas temporárias ou permanentes como ambientes reprodutivos; os ovos são depositados diretamente na água, onde os girinos se desenvolvem até a metamorfose (Bastos et al. 2003, Toledo \& Haddad 2005, Vasconcelos \& Rossa-Feres 2005). Esteve sempre associada a ambientes da borda da EEC, encontrada somente na segunda etapa de amostragem, sendo comuns grandes agregações reprodutivas em represas e açudes permanentes em áreas abertas, principalmente no início da estação chuvosa.

\section{Scinax fuscovarius (A. Lutz, 1925) - Figura 51}

Amplamente distribuída em fitofisionomias abertas da parte centro-oriental da América do Sul, pode também estar presente em taxocenoses de ambientes florestais. Muitas vezes tratada como invasora em ambientes alterados (Bertoluci \& Heyer 1995), sua área de ocorrência abrange o centro-oeste, sudeste e sul do Brasil, além do sul da Bahia, nordeste da Argentina, Paraguai e Bolívia, em altitudes que variam de 150 a 1.800 m (Frost 2009). Reproduz-se durante toda a estação quente e chuvosa (Bertoluci 1998, Bertoluci \& Rodrigues 2002b, Toledo et al. 2003, Brasileiro et al. 2005, Rodrigues et al. 2005, Santos et al. 2007), predominantemente em corpos d'água temporários de áreas abertas ou clareiras (Bertoluci \& Rodrigues 2002a, Santos et al. 2007). Porém, grandes agregações no início da estação e evidências de reprodução explosiva já foram relatadas em localidades de Mata Atlântica (Bertoluci 1998, Bertoluci \& Rodrigues 2002b). Durante todo o período estudado, só foram verificadas grandes agregações reprodutivas dessa espécie em áreas abertas na borda da EEC, porém com alguns indivíduos jovens e adultos $(\mathrm{n}=19)$ encontrados ocasionalmente nos outros ambientes amostrados, apresentando ou não atividade de vocalização. 


\section{Scinax hiemalis (Haddad \& Pombal Jr., 1987) - Figura 5m}

Relacionada ao grupo S. catharinae (Faivovich et al. 2005), tem distribuição restrita a ambientes florestais nas formações da Floresta Atlântica (FES e Floresta Ombrófila) da porção centro-oriental do estado de São Paulo, excetuando-se a planície litorânea, em áreas com altitudes entre 700 e 900 m (IUCN 2009, Frost 2009), de forma que o presente registro torna-se o mais a oeste da sua distribuição (Botucatu/SP) (Jim 2001). Como apontado por Haddad \& Pombal Jr. (1987), essa foi a única espécie encontrada na EEC que apresentou atividade reprodutiva exclusivamente durante as noites frias de inverno, sempre em poças permanentes, adjacentes (áreas de transbordo) ou no leito de riachos, tanto aqueles inseridos em áreas da mata como em clareiras. Os machos vocalizam empoleirados nos ramos da vegetação entre 10 e $70 \mathrm{~cm}$ da altura, sendo os ovos depositados próximo à superfície da água, onde formam massas aderidas à vegetação submersa (Haddad \& Pombal Jr. 1987).

13. Scinax perereca Pombal Jr., Haddad \& Kasahara, 1995 Figura 5n

Conhecida apenas de localidades na Floresta Atlântica de São Paulo ao Rio Grande do Sul, no Brasil, além de Misiones, na Argentina, e algumas localidades no oeste do Paraguai, em áreas com até $1.000 \mathrm{~m}$ de altitude (Frost 2009), essa espécie é comum em todas as partes de sua distribuição, com exceção do Paraguai (IUCN 2009). Segundo Pombal Jr. et al. (1995), em áreas de Floresta Ombrófila, apresentam agregações reprodutivas durante todo o ano em poças permanentes de áreas abertas, da borda da mata ou em clareiras, onde os machos vocalizam sobre a vegetação em posição vertical e alturas que variam entre 25 e $100 \mathrm{~cm}$. Entretanto, devido à marcada estação seca da EEC, foram observadas agregações reprodutivas somente em poças temporárias na área nuclear da Estação, apenas durante a estação chuvosa. Essa espécie foi tratada como $S$. $x$-signatus em Bertoluci et al. (2007).

\section{Scinax rizibilis (Bokermann, 1964) - Figura 5o}

Esta espécie também se encontra alocada no grupo S. catharinae (Faivovich et al. 2005). Sua distribuição atual compreende áreas de Floresta Ombrófila do sul de São Paulo ao Rio Grande do Sul, abrangendo grande parte da faixa litorânea a partir dos $800 \mathrm{~m}$ de altitude (IUCN 2009). O presente registro representa o único em FES do planalto ocidental paulista. A estação reprodutiva dessa espécie está relacionada ao período quente e chuvoso (Bertoluci 1998, Bernarde \& Machado 2000, Conte \& Rossa-Feres 2006, 2007), com densas agregações e muitas vezes apresentando características de reprodução explosiva (Haddad et al. 1990). Os ambientes reprodutivos incluem corpos d'agua permanentes e temporários de áreas de clareiras e da borda da mata, onde os machos vocalizam sobre a vegetação marginal a um altura de 20 a $30 \mathrm{~cm}$ (Bertoluci \& Rodrigues 2002a). Essa espécie é a única entre os hilídeos a apresentar desova em ninhos de espuma (Haddad et al. 1990), fato também registrado na EEC (Figura 5p).

\section{FAMÍLIA HYLODIDAE}

1. Crossodactylus cf. caramaschii Bastos \& Pombal Jr., 1995 Figura $4 \mathrm{e}$

Único representante da família Hylodidae na EEC, essa espécie pertence ao grupo C. gaudichaudii (Bastos \& Pombal Jr. 1995), e devido a certa complexidade em sua taxonomia, não é segura sua identificação específica. Tem distribuição restrita e fortemente associada a áreas bem preservadas da Floresta Atlântica do sudeste do estado de São Paulo, nas bacias hidrográficas do Alto Paranapanema e Ribeira de Iguape (IUCN 2009, Frost 2009). É uma espécie diurna, que vive associada a riachos de fundo arenoso e matriz rochosa de áreas florestais, com modo reprodutivo associado a esses ambientes (Dixo \& Verdade 2006), e possivelmente sem envolver amplexo ou com amplexo de curta-duração, sendo os ovos colocados em tocas sob pedras no leito dos córregos, como relatado para C. gaudichaudii (Weygoldt \& Carvalho-e-Silva 1992). Na EEC só foi encontrada em riachos de águas claras e leito rochoso (montante alta das micro-bacias), sempre sombreados por floresta, apresentando picos de atividade após chuvas torrenciais em dias quentes de verão. Essa espécie foi tratada como Hylodes sp. em Bertoluci et al. (2007).

\section{FAMÍLIA LEIUPERIDAE}

\section{Eupemphix nattereri Steindachner, 1863 - Figura $4 \mathrm{f}$}

Sua distribuição, que se estende pelo centro-oeste e sudeste do Brasil e leste da Bolívia e do Paraguai (Frost 2009), está associada basicamente a áreas de cerrado (e.g. Brasileiro et al. 2005, Ribeiro Jr. \& Bertoluci 2009). Os machos vocalizam em torno de corpos d'água temporários e permanentes, e o casal em amplexo constrói ninhos de espuma flutuantes, que evitam o dessecamento dos ovos em poças temporárias (Vizotto 1967, Cei 1980). Formam grandes agregações em poças e outros ambientes lênticos em áreas abertas, principalmente depois de chuvas fortes no início e ao longo da estação chuvosa (Brasileiro et al. 2005, Santos et al. 2007). Durante as fortes chuvas do início da estação chuvosa, foram avistados jovens e adultos $(n=28)$ deslocando-se pelas trilhas e estradas do interior da EEC, indicando que, mesmo considerada como típica de áreas abertas (cerrado), essa espécie faz algum uso dos remanescentes de mata da região, com sua reprodução registrada apenas nos ambientes da borda da EEC.

\section{Physalaemus cuvieri Fitzinger, 1826 - Figura 4g}

Essa espécie tem ampla ocorrência pelos biomas brasileiros, e é muito comum nas localidades onde ocorre, sendo encontrada em fitofisionomias florestais ou mesmo em áreas abertas e alteradas (IUCN 2009). Ocorre desde a Amazônia oriental até o Rio Grande do Sul, parte oriental da Bolívia, Paraguai e nordeste da Argentina (Frost 2009). Grandes agregações reprodutivas podem ser encontradas ao longo da estação quente e chuvosa (Bertoluci 1998, Bertoluci \& Rodrigues 2002a, Toledo et al. 2003, Brasileiro et al. 2005, Canelas \& Bertoluci 2007), quando os machos vocalizam dentro da água, escondidos sob a vegetação marginal. Durante o amplexo, o casal produz um ninho de espuma que é ancorado à vegetação (Bertoluci 1991, Rossa-Feres \& Jim 2001, Bertoluci \& Rodrigues 2002b, Toledo et al. 2003). Na EEC, P. cuvieri foi observada reproduzindose em todos os tipos de ambientes, tanto no interior como na borda da floresta, o que contrasta com os dados de Bertoluci \& Rodrigues (2002a) para o Parque Estadual de Intervales (SP), onde a espécie nunca utilizou ambientes do interior da mata.

3. Physalaemus marmoratus (Reinhardt and Lütken, 1862 "1861”) - Figura 4h

O status taxonômico dessa espécie manteve-se incerto para as populações do sudeste por muito tempo, tendo sido restabelecido somente após recente revisão (Nascimento et al. 2006). Ocorre em todo centro-oeste, sudeste e sul do Brasil, além de áreas adjacentes do Paraguai. Os machos vocalizam próximo de plantas herbáceas, flutuando em águas rasas de 
corpos d'água temporários, após chuvas fortes durante a estação chuvosa e final da estação seca (Rossa-Feres \& Jim 2001, Brasileiro et al. 2005). O casal em amplexo deposita seus ovos em ninhos de espuma, e os girinos desenvolvem-se no mesmo local da desova (Rossa-Feres \& Jim 2001, Brasileiro et al. 2005). Na EEC, só foi encontrada em reprodução depois de fortes chuvas no início da estação chuvosa de 2008 , em poças temporárias na borda da mata.

4. Physalaemus cf. olfersii (Lichtenstein \& Martens, 1856) - Figura 4i

Integrante do grupo de mesmo nome juntamente com outras quatro espécies (Nascimento et al. 2006), P. olfersii é tipicamente encontrada nas diversas formações da Floresta Atlântica do sudeste e sul do Brasil (Cruz et al. 2008). Dada sua extensa distribuição geográfica (estados do ES, RJ, SP, PR e SC) e grande variação morfológica, há a possibilidade de representar um complexo de espécies (Cruz et al. 2008), não tendo sido possível determinar essa espécie com precisão. Encontra-se ativa durante a noite, principalmente no início e durante a estação chuvosa (Bertoluci 1998, Bertoluci \& Rodrigues 2002b, Conte \& Rossa-Feres 2006, 2007). Os machos vocalizam no chão, abrigados na base da vegetação emergente, próximo a corpos d'água do interior e da borda da mata e de áreas abertas, incluindo clareiras (Bertoluci \& Rodrigues 2002a, Dixo \& Verdade 2006). Os ovos são depositados em um ninho de espuma de forma circular na beira da água (Figura 4t) (Heyer et al. 1990). Na EEC, só foi encontrada em ambientes bempreservados do interior da floresta, em agregações com poucos indivíduos $(\mathrm{n}=8)$.

\section{FAMÍLIA LEPTODACTYLIDAE}

\section{Leptodactylus chaquensis Cei, 1950 - Figura $4 \mathrm{j}$}

Espécie do grupo de L. latrans (antigo L. ocellatus; Lavilla et al. 2010), tem ampla distribuição geográfica, quase sempre associada ao sistema Chaco-Pantanal, registrada do norte da Argentina, leste da Bolívia e Paraguai, e norte do Uruguai, até os estados do Mato Grosso do Sul e Rio Grande do Sul (Santos \& Cechin 2008, Frost 2009) e na região noroeste do estado de São Paulo (Vasconcelos \& Rossa-Feres 2005). Os machos vocalizam e se reproduzem em poças e áreas alagadas (Prado et al. 2000, Vasconcelos \& Rossa-Feres 2005), com ou sem vegetação baixa (gramíneas e herbáceas). O período reprodutivo ocorre durante a estação chuvosa (Prado et al. 2000) e, na região noroeste do estado de São Paulo, a maior abundância de machos em vocalização foi registrada nos primeiros meses da estação chuvosa (setembro e outubro) (Vasconcelos \& Rossa-Feres 2005). Como nas demais espécies do grupo, os ovos são depositados em ninhos de espuma flutuantes, e a fêmea permanece com os ovos e os girinos, deslocando-se pelo corpo d'água, sendo acompanhada pelos girinos (Prado et al. 2000). Aparentemente essa espécie é pouco abundante na EEC, onde foram encontrados apenas dois machos adultos e que não apresentaram atividade reprodutiva.

2. Leptodactylus cf. furnarius Sazima and Bokermann, 1978 Figura 4k

Espécie do grupo de L. fuscus, distribui-se nas regiões central e sudeste do Brasil, Uruguai, centro-leste do Paraguai e nordeste da Argentina (Frost 2009). As espécies desse grupo constroem câmaras subterrâneas onde depositam os ovos em ninhos de espuma (Giaretta \& Kokubum 2004). Apresenta atividade reprodutiva em corpos d'agua permanentes e rasos, com pouca ou nenhuma vegetação recobrindo o solo (Jim 1980, Achaval \& Olmos 2003,
Eterovick \& Sazima 2004, Baldo et al. 2008). Os machos vocalizam escondidos sob touceiras de gramíneas altas, sobre solo úmido nas margens dos corpos d'água, geralmente nas proximidades das tocas (Achaval \& Olmos 2003; Eterovick \& Sazima 2004). Parece ser uma espécie com populações amplamente distribuídas, mas localmente pouco abundante (Canavero et al. 2001, Vasconcelos \& Rossa-Feres 2005, Zank et al. 2008), característica também presente na população da EEC. Entretanto, segundo Jim (1980), sua baixa abundância pode ser um artefato do hábito de vocalizar escondida, o que a torna difícil de ser registrada. Apenas um indivíduo sub-adulto foi capturado pelas armadilhas, dificultando sua identidade precisa, porém sua vocalização foi gravada em alguns dos ambientes amostrados na borda da EEC.

\section{Leptodactylus fuscus (Schneider, 1799) - Figura 41}

Trata-se de uma espécie com ampla distribuição na América do Sul a leste dos Andes, ocorrendo em diversas formações vegetais (savanas até formações florestais), estendendo-se ao leste da Colômbia, por toda a Venezuela, Guianas, Brasil, Paraguai e leste da Bolívia (Frost 2009). O período reprodutivo está associado à estação chuvosa (Bertoluci 1998, Bernarde \& Kokubum 1999, Vasconcelos \& Rossa-Feres 2005). Os machos vocalizam e constroem tocas nas margens de lagoas temporárias de áreas abertas (Cei 1980, Rossa-Feres \& Jim 2001, Bertoluci \& Rodrigues 2002a, Brasileiro et al. 2005). Os ovos são depositados na forma de ninhos de espuma dentro da toca, onde os girinos passam pelos primeiros estágios de desenvolvimento, que se completa no corpo d'água principal (Toledo et al. 2003). Foi encontrada em atividade de vocalização apenas em ambientes de área aberta na borda da EEC ou em clareiras, com grandes agregações reprodutivas após fortes chuvas no começo e no meio da estação chuvosa.

\section{Leptodactylus labyrinthicus (Spix, 1824) - Figura 4m}

Dentro do grupo L. pentadactylus, que inclui os grandes leptodactilídeos centro e sul-americanos (Heyer 1979), até recententemente incluía outras duas espécies (L. turimiquensis e L. vastus) tratadas como L. labyrinthicus (Heyer 2005). Tem sua distribuição abrangendo diversos biomas brasileiros, principalmente formações abertas, como os cerrados em enclaves amazônicos e da região centro-oeste, estendendo-se ao sudeste e sul do Brasil, além do leste do Paraguai e algumas localidades na Bolívia (Frost 2009). Sua reprodução está associada ao período mais quente e chuvoso do ano (Brasileiro et al. 2005, Vasconcelos \& Rossa-Feres 2005); apenas quatro indivíduos foram encontrados em atividade reprodutiva apenas na borda da EEC, no início da estação chuvosa. Os machos vocalizam nas margens ou dentro da água em partes rasas de poças ou lagoas, onde, após o amplexo, o casal deposita os ovos em um grande ninho de espuma coberto ou circundado pela vegetação (Zina \& Haddad 2005). Ocorreu em baixa abundância no interior da EEC $(\mathrm{n}=5)$, mas é freqüente em áreas agrícolas do entorno (RAB, obs. pess.), fato que pode indicar a baixa associação dessa espécie com ambientes florestais.

\section{Leptodactylus mystaceus (Spix, 1824) - Figura 4n}

Também dentro do grupo L. fuscus e por vezes confundida com outras espécies crípticas do grupo (L. elenae, L. didymus e L. notoaktites), essa espécie ocupa diversos biomas do Brasil e da América do Sul (Heyer et al. 1996), estendendo-se a leste dos Andes em altitudes abaixo dos $1.000 \mathrm{~m}$, desde a Colômbia, Venezuela, Guianas, Suriname, passando ao sul pelo Equador, Peru e Bolívia, em toda a bacia Amazônica até o sudeste do Brasil (Frost 2009), ocupando fitofisionomias florestais e ab- 
ertas (IUCN 2009). O período reprodutivo dessa espécie está associado à estação quente e chuvosa (Rossa-Feres \& Jim 1994, Toledo et al. 2003), e os machos são frequentemente encontrados em atividade vocal do crepúsculo ao meio da noite, em charcos e alagados da borda da floresta ou em áreas abertas próximo a fragmentos florestais. Também constroem tocas subterrâneas, onde a desova é depositada antes de ser submersa pela elevação no nível do corpo d'água, onde os girinos completam seu desenvolvimento (Heyer 1978, Toledo et al. 2005). Essa espécie ocorreu em corpos d'água temporários somente no interior da EEC, apresentando grandes agregações nos meses com maior pluviosidade, iniciando sua atividade de vocalização antes do período crepuscular.

\section{Leptodactylus mystacinus (Burmeister, 1861) - Figura 4o}

Considerado como um complexo de espécies, também dentro do grupo L. fuscus, ocupa tanto formações vegetais abertas, como o Cerrado e a Caatinga, como formações florestais dentro do domínio da Floresta Atlântica e áreas com grandes perturbações antrópicas (IUCN 2009). De ampla distribuição geográfica, ocorre pela Zona da Mata em Pernambuco e partes do Piauí e Maranhão ao norte, pelo Tocantins, Bahia, Goiás e Mato Grosso do Sul, no centro-oeste, além das regiões sudeste e sul do Brasil, alcançando o sudeste da Bolívia, o centro da Argentina e todo o Paraguai e Uruguai (IUCN 2009, Frost 2009). Assim como outras espécies do grupo, possui parte do desenvolvimento em ninhos de espuma depositados na toca subterrânea construída pelo macho (Heyer 1978, Cei 1980). A reprodução ocorre do final da estação seca até o final da estação chuvosa (Bernarde \& Kokubum 1999, Toledo et al. 2003, Brasileiro et al. 2005). Durante o período estudado, apresentou atividade vocal quase contínua com baixas abundâncias locais, mas com grande frequência pelos corpos d'água amostrados, tanto aqueles na borda como no interior da EEC.

\section{Leptodactylus cf. latrans - Figura $4 \mathrm{p}$}

Neótipos de L. latrans (Steffen, 1815) foram recentemente designados por Lavilla et al. (2010) e essa espécie é considerada sinônimo sênior de L. ocellatus. A associação de um espécime-tipo a uma localidade-tipo é crítica para as espécies de Leptodactylus, as quais podem representar complexos de espécies (de Sá et al. 2007). A distribuição geográfica de Leptodactylus cf. latrans (antigo L. ocellatus) é ampla em alguns países da América do Sul a leste dos Andes, como Brasil, Uruguai, Paraguai e Argentina (Frost 2009). Contudo, alguns autores sugeriram que existam populações de espécies diferentes sendo tratadas como L. ocellatus (Cei 1980, Heyer et al. 2006). Os machos vocalizam ao nível d'água em ambientes aquáticos localizados em áreas abertas ou na borda da mata (Bertoluci \& Rodrigues 2002a). Os ovos são depositados em ninhos de espuma flutuantes e a fêmea permanece com os ovos e girinos, protegendo-os de predadores (Vaz-Ferreira \& Gehrau 1975, Bertoluci 1991). Os girinos dessa espécie são gregários, deslocando-se em cardumes (Cei 1980). A reprodução ocorre ao longo da estação quente e chuvosa (Bertoluci 1998, Bertoluci \& Rodrigues 2002b, Conte \& Rossa-Feres 2006, Canelas \& Bertoluci 2007). Na EEC esta espécie só exibiu atividade reprodutiva em ambientes de áreas abertas da borda ou em clareiras, sempre em baixas abundâncias $(n=3)$ e com período reprodutivo associado ao início das chuvas, em outubro.

\section{Leptodactylus podicipinus (Cope, 1862) - Figura 4q}

Típico de formações vegetais mais abertas, esse leptodactilídeo é comum por todo o centro-leste da América do Sul, do Paraguai ao sul do Uruguai, Argentina, Bolívia, algumas áreas do sudeste, sul, parte central do Brasil e ao longo dos rios Madeira e
Amazonas, em altitudes maiores que 550 m (Frost 2009). Habita áreas ripárias, vivendo e se reproduzindo entre as plantas e raízes que cobrem as margens de rios, várzeas e lagoas temporárias e permanentes adjacentes (Cei 1980, Santos et al. 2007). Os ovos são depositados em águas rasas, onde as larvas desenvolvem-se até a metamorfose (Cei 1980, Prado et al. 2000). Os machos podem vocalizar ao longo de todo o ano, com pico de reprodução na estação chuvosa (Bernarde \& Kokubum 1999, Prado et al. 2000, Santos et al. 2007). Foi encontrado apenas em um ambiente na borda de EEC na segunda etapa de amostragem, com poucos machos em atividade de vocalização $(n=5)$ após fortes chuvas em janeiro de 2009.

\section{FAMÍLIA MICROHYLIDAE}

\section{Chiasmocleis albopunctata (Boettger, 1885) - Figura 4r}

Ocorre na parte oriental da Bolívia, Paraguai e, no Brasil, nos estados de Goiás, Mato Grosso, Mato Grosso do Sul, Minas Gerais e São Paulo, em altitudes compreendidas entre 100 e $1500 \mathrm{~m}$ (Frost 2009). Grandes agregações de machos vocalizando com o corpo parcialmente submerso podem ser encontradas em corpos d'água temporários e em pequenas poças formadas por chuvas fortes, ao longo da estação chuvosa (Toledo et al. 2003, Brasileiro et al. 2005). Os ovos são depositados em corpos d'agua lênticos, onde os girinos se desenvolvem até a metamorfose (Toledo et al. 2003). Essa espécie foi registrada apenas na segunda etapa da amostragem, em atividade reprodutiva após chuvas intensas (acima de $30 \mathrm{~mm}$ ), nos meses de dezembro e janeiro, em grandes agregações características de reprodução explosiva (Wells 1977), somente em açudes temporários na borda de EEC.

\section{Elachistocleis cf. ovalis (Schneider, 1799) - Figura 4s}

Devido a diversas controvérsias sobre o status taxonômico das populações que ocorrem no sudeste do Brasil, adotamos para essa espécie o táxon com maior abrangência, diferente do proposto por Lavilla et al. (2003), porém concordamos com a necessidade de revisão taxonômica no grupo, remetendo a não definição específica deste táxon. Ocorre do Panamá, Colômbia pelo leste dos Andes, no sudeste da Bolívia, região central do Brasil e no estado de São Paulo (Frost 2009, IUCN 2009). O período reprodutivo está relacionado com a ocorrência de altas precipitações pluviométricas ao longo da estação quente e chuvosa, mas com maior abundância em plena estação chuvosa (Rodrigues et al. 2003, Vasconcelos \& Rossa-Feres 2005), e os ovos são depositados na forma de uma película delgada na superfície de águas rasas, geralmente em poças temporárias de áreas abertas (Rodrigues et al. 2003). Na EEC foi encontrada em atividade reprodutiva apenas em ambientes na borda, no início da estação chuvosa ou após chuvas fortes em janeiro.

A anurofauna da EEC é largamente dominada por espécies da família Hylidae, a exemplo de várias outras localidades brasileiras cobertas por diversas formações vegetais: Floresta Ombrófila Densa (Heyer et al. 1990, Bertoluci \& Rodrigues 2002a,b, Guix et al. 1994, 2000, Bertoluci et al. 2007), Floresta de Restinga (Bertoluci et al. 2007, Narvaes et al. 2009), Floresta Estacional Semidecidual (e.g. Jim 1980, Haddad \& Sazima 1992, Rossa-Feres \& Jim 1994, Toledo et al. 2003, Vasconcelos \& Rossa-Feres 2005, Santos et al. 2007, 2009, Zina et al. 2007,), Cerrado (Brasileiro et al. 2005, Ribeiro Jr. \& Bertoluci, 2009), Floresta Ombrófila Mista (Conte \& Machado 2005, Conte \& Rossa-Feres 2007) e Floresta Amazônica (e.g. Aichinger 1987, Gascon 1991, Gordo 2003, Lima et al. 2006), além de áreas de transição entre Mata Atlântica e Cerrado (Kopp \& Eterovick 
2006, Canelas \& Bertoluci 2007) e entre Floresta Ombrófila Densa e Floresta Ombrófila Mista (Conte \& Rossa-Feres 2006).

A taxocenose de anfíbios anuros da EEC possui elementos que nos permitem classificá-la como uma área de transição entre as faunas de Floresta Ombrófila e aquelas de formações mais abertas do Chaco-Cerrado com acentuada sazonalidade. Algumas das espécies de Hylidae registradas na EEC estão muito mais relacionadas a taxocenoses de regiões mais secas, como o cerrado ou matas-de-galeria do interior, do que com taxocenoses de Floresta Ombrófila, contando com espécies de ampla distribuição geográfica e com grande capacidade de ocupar ambientes alterados, como Dendropsophus elianeae, D. minutus, D. nanus, Hypsiboas albopunctatus, Scinax fuscomarginatus e S. fuscovarius (Bernarde \& Kokubum 1999, Vasconcelos \& Rossa-Feres 2005, Santos et al. 2007). Esse padrão também foi verificado para as espécies da família Leptodactylidae (Leptodactylus chaquensis, L. furnarius, L. fuscus, L. labyrinthicus, L. cf. latrans, L. mystaceus, L. mystacinus, L. podicipinus), frequentemente associadas a áreas antropizadas ou a fitofisionomias abertas e que, quando ocorrem em áreas de Floresta Ombrófila, apresentam grande plasticidade quanto ao uso de habitat (Cei 1980, Heyer et al. 1990, Bertoluci \& Rodrigues 2002a, Prado et al. 2002). Também observamos que, quando áreas do entorno da unidade de conservação foram amostradas (segunda etapa do trabalho), tivemos o registro de espécies típicas de formações mais abertas e/ou alteradas (D. elianeae, S. fuscomarginatus, P. marmoratus, L. furnarius, L. podicipinus e C. albopunctata). Segundo Haddad \& Prado (2005), uma situação comum após o desmatamento é a invasão das áreas desmatadas por espécies típicas de áreas de cerrado ou formações abertas, que são mais resistentes ao dessecamento e têm modos reprodutivos mais generalizados ou adaptados a micro-habitats sujeitos à insolação e a períodos de seca. As espécies acima relacionadas reúnem essas características e, eventualmente, são registradas em áreas de mata, como é o caso de L. furnarius, L. podicipinus e C. albopunctata (RAB, obs. pess.), podendo ser potencialmente favorecidas caso ocorra a supressão da vegetação nativa.

Por outro lado, na EEC também foram encontradas espécies de distribuição mais restrita e fortemente associadas a florestas mais úmidas do domínio da Floresta Atlântica, como Vitreorana uranoscopa, Phyllomedusa tetraploidea, Itapotihyla langsdorffii, Scinax hiemalis, S. perereca, S. rizibilis, Crossodactylus caramaschii e Haddadus binotatus (Heyer et al. 1990, Pombal Jr. et al. 1995, Bertoluci 1998, Machado et al. 1999, Bertoluci \& Rodrigues 2002a, Toledo et al. 2003, Pombal Jr. \& Haddad 2005, Dixo \& Verdade 2006, Bertoluci et al. 2007), evidenciando seu caráter de região de transição entre diferentes formações vegetais. Entre os bufonídeos e os leiuperídeos da área, também há espécies associadas tanto ao cerrado (Eupemphix nattereri, Physalaemus marmoratus e Rhinella schneideri; Nomura et al. 2003, Nascimento et al. 2006) como ao domínio da Floresta Atlântica (Physalaemus cf. olfersii, Rhinella ornata; Baldissera Jr. et al. 2004, Haddad \& Prado 2005).

A severidade climática decorrente da extensa e pronunciada estação seca das áreas de planalto do interior paulista (Duellman 1999, Santos et al. 2007), a imprevisibilidade e inconstância das chuvas no início da estação chuvosa (Rossa-Feres \& Jim 2001), juntamente com o elevado grau de conversão do ambiente natural em áreas de cultivo (Rossa-Feres et al. 2008, Ribeiro et al. 2009), são os prováveis fatores responsáveis pelo predomínio de espécies generalistas no noroeste do estado de São Paulo e, provavelmente, em toda a área originalmente recoberta por Floresta Estacional Semidecidual (Rossa-Feres \& Jim 2001, Santos et al. 2007). Esses dados, quando contrastados com o registro de espécies com reconhecida exigência quanto às características do hábitat e com modos reprodutivos especializados, como as representantes das famílias Centrolenidae (V. uranoscopa),
Hylodidae (Crossodactylus caramaschii) e Crausgastoridae (Haddadus binotatus), indicam que a área apresenta um bom estado de conservação. Sua ocorrência nessa área deve-se a fatores históricos de colonização e dispersão, principalmente em função da proximidade da EEC com a Floresta Atlântica, que é considerada um centro de diversificação de anuros (Duellman 1999), e por sustentar populações dessas espécies associadas a habitats florestais, a área pode ser considerada como apresentando um bom estado de conservação.

Nenhuma espécie registrada na área de estudo encontra-se na lista de espécies ameaçadas do Estado de São Paulo (SMA 2009), do Brasil (Machado et al. 2005) ou da IUCN (Stuart et al. 2008). Esse fato, contudo, não reduz a importância dessa unidade de conservação, pois abriga populações de diversas espécies (e.g. Hypsiboas lundii, Itapotihyla langsdorffi, Scinax hiemalis, S. rizibilis, Vitreorana uranoscopa) consideradas em declínio pela IUCN (2009). Essas populações são importantes para a manutenção da diversidade genética regional, pois, mesmo espécies com alta capacidade de dispersão (como Rhinella ornata), podem, ao longo do tempo, sofrer os efeitos genéticos negativos da fragmentação, que podem resultar em declínios populacionais ou extinções locais (Dixo et al. 2009). Embora não haja dados quantitativos para estabelecer com segurança esses declínios, acreditamos que o princípio da precaução (Groom et al. 2006) deva ser respeitado, e medidas preventivas que garantam a continuidade dessas populações devem ser tomadas com a máxima urgência.

\section{Agradecimentos}

Os autores agradecem à FAPESP pelo apoio financeiro (processos 04/15938-5 e 99/09635-0) e pelas bolsas de Iniciação Científica e Mestrado concedidas a RAB (processos 06/55363-7 e 08/024764), ao CNPq pela bolsa de Iniciação Científica concedida a RAB, a Vanessa K. Verdade pela ajuda na identificação das espécies, a Célio F. B. Haddad pela permissão a consulta da Coleção Cientifica CFBH-UNESP/IB, ao IBAMA pelas licenças de coleta $\left(\mathrm{n}^{\circ} 430 / 05\right.$ e 15721-1), ao Instituto Florestal de São Paulo pela permissão de acesso à unidade de conservação e aos biólogos José Wagner Ribeiro Jr., Henrique O. Sawakuchi, Vívian M. F. N. Vilela, Paula C. Lopes, Thiago S. Marques, Leonardo Ramos Adriano e Lucas B. Crivellari pelo auxílio nos trabalhos de campo. DCRF e JB são bolsistas de produtividade do CNPq.

\section{Referências}

ACHAVAL, F. \& OLMOS, A. 2003. Anfibios y reptiles del Uruguay. 2 ed. Graphis Ltda, Montevideo.

AICHINGER, M. 1987. Annual activity patterns of anurans in a seasonal Neotropical environment. Oecologia 71(4):583-592.

ARAUJO, C.O., CONDEZ, T.H. \& SAWAYA, R.J. 2009. Anfíbios Anuros do Parque Estadual das Furnas do Bom Jesus, sudeste do Brasil, e suas relações com outras taxocenoses no Brasil. Biota Neotrop. 9(2):http:// www.biotaneotropica.org.br/v9n2/pt/abstract?article+bn01109022009 (último acesso em 10/11/2009).

ARZABE, C. \& LOEBMANN, D. 2006. Amphibia, Hylidae, Itapotihyla langsdorffi: distribution extension. Check List 2(2):33-34.

BALDISSERA JÚNIOR, F.A., CARAMASCHI, U. \& HADDAD, C.F.B. 2004. Review of the Bufo crucifer species group, with descriptions of two new related species (Amphibia, Anura, Bufonidae). Arq. Mus. Nac. 62(3):255-282.

BALDO, D., TOMATIS, C. \& SEGALLA, M.V. 2008. Amphibia, Anura, Leptodactylidae, Leptodactylus furnarius: new country record, geographic distribution map and advertisement call. Check List 4(2):98-102.

BASTOS, R.P. \& POMBAL Jr., J.P. 1995. New species of Crossodactylus (Anura, Leptodactylidae) from the Atlantic rainforest of southeastern Brazil. Copeia 1995(2):436-439. 
BASTOS, R.P., MOTTA, J.A.O., LIMA, L.P. \& GUIMARÃES, L.D. 2003. Anfíbios da Floresta Nacional da Silvânia, Estado de Goiás. Stylo Gráfica e Editora, Goiânia.

BERNARDE, P.S. \& ANJOS, L. 1999. Distribuição espacial e temporal da anurofauna no Parque Estadual Mata dos Godoy, Londrina, Paraná, Brasil (Amphibia: Anura). Comun. Mus. Cienc. Tecnol. PUCRS, Sér. Zool. 12(1):127-140.

BERNARDE, P.S. \& KOKUBUM, M.N.C. 1999. Anurofauna do Município de Guararapes, Estado de São Paulo, Brasil (Amphibia: Anura). Acta Biol. Leopoldensia 21(1):89-97.

BERNARDE, P.S. \& MACHADO, R.A. 2000. Riqueza de espécies, ambientes de reprodução e temporada de vocalização da anurofauna em Três Barras do Paraná, Brasil (Amphibia: Anura). Cuad. Herpetol. 14(2):93-104.

BERTOLUCI, J. 1991. Partição de recursos associada à atividade reprodutiva em uma comunidade de anuros (Amphibia) de Mata Atlântica. Dissertação de Mestrado, Universidade de São Paulo, São Paulo.

BERTOLUCI, J. 1998. Annual patterns of breeding activity in Atlantic Rainforest anurans. J. Herpetol. 32(4):607-611.

BERTOLUCI, J. \& HEYER, W.R. 1995. Boracéia update. Froglog 14:2-3.

BERTOLUCI, J. \& RODRIGUES, M.T. 2002a. Utilização de hábitats reprodutivos e micro-hábitats de vocalização em uma taxocenose de anuros (Amphibia) da Mata Atlântica do sudeste do Brasil. Pap. Avul. Zool. 42(11):287-297.

BERTOLUCI, J. \& RODRIGUES, M.T. 2002b. Seasonal patterns of breeding activity of Atlantic rainforest anurans at Boracéia, Southeastern Brazil. Amphibia-Reptilia 23(2):161-167.

BERTOLUCI, J., BRASSALOTI, R.A., RIBEIRO Jr., J.W., VILELA, V.M.F.N. \& SAWAKUCHI, H.O. 2007. Species composition and similarities among anuran assemblages of forest sites in southeastern Brazil. Sci. Agric. 64(4):364-374.

BRASILEIRO, C.A., SAWAYA, R.J., KIEFER, M.C. \& MARTINS, M. 2005. Amphibians of an open cerrado fragment in southeastern Brazil. Biota Neotrop. 5(2): http://www.biotaneotropica.org.br/v5n2/pt/ abstract?article+BN00405022005 (último acesso em 10/03/2009).

CANAVERO, A., NAYA, D.E. \& MANEYRO, R. 2001. Leptodactylus furnarius Sazima y Bokermann, 1978 (Anura: Leptodactylidae). Cuad. Herpetol. 15(1):89-91.

CANELAS, M.A.S. \& BERTOLUCI, J. 2007. Anurans of the Serra do Caraça, southeastern Brazil: species composition and phenological patterns of calling activity. Iheringia, Ser. Zool. 97(1):21-26.

CARNAVAL, A.C., HICKERSON, M.J., HADDAD, C.F.B., RODRIGUES, M.T. \& MORITZ, C. 2009. Stability predicts genetic diversity in the Brazilian Atlantic Forest Hotspot. Science 323(5915):785-789.

CARVALHO e SILVA, A.M.T., SILVA, G.R. \& CARVALHO e SILVA, S.P. 2008. Anuros da Reserva Rio das Pedras, Mangaratiba, RJ, Brasil. Biota Neotrop. 8(1): http://www.biotaneotropica.org.br/v8n1/pt/ fullpaper?bn02608012008 (último acesso em 10/03/2009).

CECHIN, S.Z. \& MARTINS, M. 2000. Eficiência de armadilhas de queda (pitfall traps) em amostragens de anfíbios e répteis no Brasil. Rev. Bras. Zool. 17(3):729-749.

CEI, J.M. 1980. Amphibians of Argentina. Monit. Zool. Ital. Monogr. 2:1-609.

CISNEROS-HEREDIA, D.F. \& MCDIARMID, R.W. 2007. Revision of the characters of Centrolenidae (Amphibia: Anura: Athesphatanura), with comments on its taxonomy and the description of new taxa of glassfrogs. Zootaxa 1572:1-82.

COLWELL, R.K., MAO, C.X. \& CHANG, J. 2004. Interpolating, extrapolating, and comparing incidence-based species accumulation curves. Ecology 85(10):2717-2727.

COLWELL, R.K. 2005. EstimateS: statistical estimation of species richness and shared species from samples. Versão 7.5.2. University of Connecticut, Storrs. http://viceroy.eeb.uconn.edu/estimates (último acesso em $1 / 09 / 2009)$

CONDEZ, T.H., SAWAYA, R.J. \& DIXO, M. 2009. Herpetofauna dos remanescentes de Mata Atlântica da região de Tapiraí e Piedade, SP, sudeste do Brasil. Biota Neotrop. 9(1):http://www.biotaneotropica. org.br/v8n4/pt/abstract?article+bn01809012009 (último acesso em $10 / 11 / 2009)$.

CONTE, C.E. \& MACHADO, R.A. 2005. Riqueza de espécies e distribuição espacial e temporal em comunidades de anuros (Amphibia, Anura) em uma localidade de Tijucas do Sul, Paraná, Brasil. Rev. Bras. Zool. 22(4):940-948.

CONTE, C.E. \& ROSSA-FERES, D.C. 2006. Diversidade e ocorrência temporal da anurofauna (Amphibia, Anura) em São José dos Pinhais, Paraná, Brasil. Rev. Bras. Zool. 23(1):162-175.

CONTE, C.E. \& ROSSA-FERES, D.C. 2007. Riqueza e distribuição espaçotemporal de anuros em um remanescente de Floresta de Araucária no sudeste do Paraná. Rev. Bras. Zool. 24(4):1025-1037.

CORN, P.S. 1994. Standard techniques for inventory and monitoring: straightline drift fences and pitfall traps. In Measuring and monitoring biological diversity: standard methods for amphibians (W.R. Heyer, M.A. Donnelly, R.W. McDiarmid, L.A.C. Hayek \& M.S. Foster, eds.). Smithsonian Institution Press, Washington, p. 108-117.

CRUMP, M.L. \& SCOTT Jr., N.J. 1994. Standard techniques for inventory and monitoring: visual encounter surveys. In Measuring and monitoring biological diversity: standard methods for amphibians (W.R. Heyer, M.A. Donnelly, R.W. McDiarmid, L.A.C. Hayek \& M.S. Foster, eds.). Smithsonian Institution Press, Washington, p. 84-92.

CRUZ, C.A.G., CASSINI, C.S. \& CARAMASCHI, U. 2008. A new species of the genus Physalaemus Fitzinger, 1826 (Anura, Leiuperidae) from Southern Brazil. S. Amer. J. Herpetol. 3(3):239-243.

DIXO, M. \& VERDADE, V.K. 2006. Herpetofauna de serrapilheira da Reserva Florestal de Morro Grande, Cotia (SP). Biota Neotrop. 6(2): http://www. biotaneotropica.org.br/v6n2/pt/abstract?article+bn00806022006 (último acesso em 10/08/2009).

DIXO, M., METZGER, J.P., MORGANTE, J.S. \& ZAMUDIO, K.R. 2009. Habitat fragmentation reduces genetic diversity and connectivity among toad populations in the Brazilian Atlantic Coastal Forest. Biol. Conserv. 142(8): 1560-1569.

DUELLMAN, W.E. 1999. Distribution patterns of amphibians in the South America. In Patterns of distribution of: a global perspective (W.E. Duellman, ed.). Johns Hopkins University Press, London, p. 255-327.

DURIGAN, G., FRANCO, G.A.D.C., SAITO, M. \& BAITELLO, J.B. 2000. Estrutura e diversidade do componente arbóreo da floresta na Estação Ecológica dos Caetetus, Gália, SP. Rev. Brasil. Bot. 23(4):371-383.

ETEROVICK, P.C. \& SAZIMA, I. 2004. Anfíbios da Serra do Cipó, Minas Gerais, Brasil. PUC Minas, Belo Horizonte.

FAIVOVICH, J., HADDAD, C.F.B., GARCIA, P.C.A., FROST, D.R., CAMPBELL, J.A. \& WHEELER, W.C. 2005. Systematic review of the frog family Hylidae, with special reference to Hylinae: phylogenetic analysis and taxonomic revision. Bull. Am. Mus. Nat. Hist. 294:1-294.

FROST, D.R. 2009. Amphibian species of the World: an online reference. Version 5.3 American Museum of Natural History, New York. http://research.amnh.org/herpetology/amphibia/ (último acesso em 12/08/2009).

GASCON, C. 1991. Population- and community-level analyses of species occurrences of central amazonian rainforest tadpoles. Ecology 72(5):1731-1746.

GIARETTA, A.A. \& KOKUBUM, M.N.C. 2004. Reproductive ecology of Leptodactylus furnarius Sazima \& Bokermann 1978 a frog that lays eggs in underground chambers (Anura, Leptodactylidae). Herpetozoa 16(3-4):115-126.

GORDO, M. 2003. Os anfíbios anuros do Baixo Rio Purus/Solimões. In Piagaçu-Purus: bases científicas para a criação de uma Reserva de Desenvolvimento Sustentável (C.P. Deus, R. Silveira \& L.H.R. Py-Daniel, eds.). Instituto de Desenvolvimento Sustentável Mamirauá, Manaus. p. 243-256.

GUAYASAMIN, J.M., CASTROVIEJO-FISHER, S., TRUEB, L., AYARZAGÜENA, J., RADA, M. \& VILÀ, C. 2009. Phylogenetic systematics of Glassfrogs (Amphibia: Centrolenidae) and their sister taxon Allophryne ruthveni. Zootaxa 2100:1-97. 
GUIX, J.C., NUNES, V.S. \& MIRANDA, J.R. 1994. Autochthonous and colonizing species of frogs in Carlos Botelho State Reserve, southeastern Brazil. Bol. Asoc. Herpetol. Esp. 5(1):8-13.

GUIX, J.C., MONTORI, A., LLORENTE, G.A., CARRETERO, M.A. \& SANTOS, X. 1998. Natural history and conservation of Bufonids in four Atlantic rainforest areas of southeastern Brazil. Herpetol. Nat. Hist. 6(1):1-12.

GUIX, J.C., LLORENTE, G., MONTORI, A., CARRETERO, M.A. \& SANTOS, X. 2000. Una nueva área de elevada riqueza de anuros em El Bosque Lluvioso Atlántico de Brasil. Bol. Asoc. Herpetol. Esp. 11(2):100-105.

GOTELLI, N.J. \& COLWELL, R.K. 2001. Quantifying biodiversity: procedures and pitfalls in the measurement and comparison of species richness. Ecol. Lett. 4:379-391.

GROOM, M.J., MEFFE, G.K. \& CARROLL, C.R. 2006. Principles of conservation biology. Sinauer Associates, Sunderland.

HADDAD, C.F.B. \& POMBAL Jr., J.P. 1987. Hyla hiemalis, nova espécies do grupo rizibilis do Estado de São Paulo (Amphibia, Anura, Hylidae). Rev. Bras. Biol. 47(1-2):127-132.

HADDAD, C.F.B. \& PRADO, C.P.A. 2005. Reproductive modes in frogs and their unexpected diversity in the Atlantic forest of Brazil. BioScience 55(3):207-217.

HADDAD, C.F.B. \& SAZIMA, I. 1992. Anfíbios anuros da Serra do Japi In História Natural da Serra do Japi: ecologia e preservação de uma área florestal no Sudeste do Brasil (L.P.C. Morellatto, org.). UNICAMP, Campinas, p. 188-211.

HADDAD, C.F.B., POMBAL Jr., J.P. \& GORDO, M. 1990. Foam nest in a hylid frog (Amphibia, Anura). J. Herpetol. 24(2):225-226.

HADDAD, C.F.B., POMBAL Jr., J.P. \& BATISTIC, R.F. 1994. Natural hybridization between diploid and tetraploid species of Leaf-frogs, genus Phyllomedusa (Amphibia). J. Herpetol. 28(4):425-430.

HAWKINS, M.A., SITES Jr., J.W. \& NOONAN, B.P. 2007. Dendropsophus minutus (Anura: Hylidae) of the Guiana Shield: using DNA barcodes to assess identity and diversity. Zootaxa 1540:61-67.

HEDGES, S.B., DUELLMAN, W.E. \& HEINICKE, M.P. 2008. New World direct-developing frogs (Anura: Terrarana): molecular phylogeny, classification, biogeography, and conservation. Zootaxa 1737:1-182.

HEYER, W.R. 1978. Systematics of the fuscus group of the frog genus Leptodactylus (Amphibia, Leptodactylidae). Nat. Hist. Mus. Los. Ang. Cty. Sci. Bull. 29:1-85.

HEYER, W.R. 1979. Systematics of the pentadactylus species group of the frog genus Leptodactylus (Amphibia: Leptodactylidae). Smithson. Contr. Zool. 301:1-43.

HEYER, W.R. 1985. Taxonomic and natural history notes on frogs of the genus Centrolenella (Amphibia: Centrolenidae) from southeastern Brazil and adjacent Argentina. Pap. Avul. Zool. 36(1):1-21.

HEYER, W.R., RAND, A.S., CRUZ, C.A.G., PEIXOTO, O.L. \& NELSON, C.E. 1990. Frogs of Boracéia. Arq. Zool. 31(4):231-410.

HEYER, W.R, GARCIA-LOPEZ, J.M. \& CARDOSO, A.J. 1996. Advertisement call variation in the Leptodactylus mystaceus species complex (Amphibia: Leptodactylidae) with a description of a new sibling species. Amphibia-Reptilia 17(1):7-31.

HEYER, W.R. 2005. Variation and taxonomic clarification of the large species of the Leptodactylus pentadactylus species group (Amphibia: Leptodactylidae) from Middle America, northern South America, and Amazonia. Arq. Zool. 37(3):269-348.

HEYER, W.R., CARAMASCHI, U. \& SÁ, R.O. 2006. Rana ocellata Linnaeus, 1758 (currently Leptodactylus ocellatus; Amphibia, Anura): proposed conservation of usage of the specific name by the designation of a neotype. Bull. Zool. Nomencl. 63(3):184-186.

INTERNATIONAL UNION FOR CONSERVATION OF NATURE AND NATURAL RESOURCES - IUCN. 2009. IUCN Red List of Threatened Species. Cambridge.http://www.iucnredlist.org/ (último acesso em 18/11/2009).
JIM, J. 1980. Aspectos ecológicos dos anfíbios registrados na região de Botucatu, São Paulo (Amphibia, Anura). Tese de Doutorado, Universidade de São Paulo, São Paulo, 332 p.

KOPP, K. \& ETEROVICK, P.C. 2006. Factors influencing spatial and temporal structure of frog assemblages at ponds in Southeastern Brazil. J. Nat. Hist. 40(29-31):1813-1830.

LAVILLA E.O., VAIRA, M. \& FERRARI, L. 2003. A new species of Elachistocleis (Anura: Microhylidae) from the Andean Yungas of Argentina, with comments on the Elachistocleis ovalis E. bicolor controversy. Amphibia-Reptilia 24(3):269-284.

LAVILLA E.O., LANGONE, J.A., CARAMASCHI, U., HEYER, W.R. \& SÁ, R.O. 2010. The identification of Rana ocellata Linnaeus, 1758. Nomenclatural impact on the species currently known as Leptodactylus ocellatus (Leptodactylidae) and Osteopilus brunneus (Gosse, 1851) (Hylidae). Zootaxa 2346:1-16.

LIMA, A.P., MAGNUSSON, W.E., MENIN, M., ERDTMANN, L.K., RODRIGUES, D.J., KELLER, C. \& HÖDL, W. 2006. Guia dos sapos da Reserva Adolpho Ducke - Amazônia Central/Guide to the frogs of Reserva Adolpho Ducke - Central Amazonia. Ed. Átezma, Manaus.

MACHADO, A.B.M., MARTINS, C.S. \& DRUMMOND, G.M. 2005. Lista da fauna brasileira ameaçada de extinção. Fundação Biodiversitas, Belo Horizonte.

MACHADO, R.A., BERNARDE, P.S., MORATO, S.A.A. \& ANJOS, L. 1999. Análise comparada da riqueza de anuros entre duas áreas com diferentes estados de conservação no município de Londrina, Paraná, Brasil (Amphibia: Anura). Rev. Bras. Zool. 16(4):997-1004.

MARTINS, M. \& HADDAD, C.F.B. 1988. Vocalization and reproductive behaviour in the smith frog, Hyla faber Wied (Amphibia:Hylidae). Amphibia-Reptilia 9(1):49-60

NASCIMENTO, L.B., PIMENTA, B.V.S., CRUZ, C.A.G. \& CARAMASCHI, U. 2006. Taxonomic status of Gomphobates marmoratus Reinhardt and Lütken, 1862 "1861" and Eupemphix fuscomaculatus Steindachner, 1864 (Amphibia, Anura, Leptodactylidae). S. Amer. J. Herpetol. 1(3):166-174.

NAPOLI, M.F. \& CARAMASCHI, U. 2000. Description and variation of a new Brazilian species of the Hyla rubicundula group. (Anura, Hylidae). Alytes 17(3-4):165-184.

NARVAES, P., BERTOLUCI, J. \& RODRIGUES, M.T. 2009. Composição, uso de hábitat e estações reprodutivas das espécies de anuros da floresta de restinga da Estação Ecológica Juréia-Itatins, Sudeste do Brasil. Biota Neotrop. 9(2): http://www.biotaneotropica.org.br/v9n2/en/ abstract?article+bn02009022009 (último acesso em 10/08/2009).

NASCIMENTO, L.B., PIMENTA, B.V.S., CRUZ, C.A.G. \& CARAMASCHI, U. 2006. Taxonomic status of Gomphobates marmoratus Reinhardt and Lutken, 1862 "1861" and Eupemphix fuscomaculatus Steindachner, 1864 (Amphibia, Anura, Leptodactylidae). S. Am. J. Herpetol. 1(3):166-174.

NOMURA, F., ROSSA-FERES, D.C. \& PRADO, V.H. 2003. The tadpole of Physalaemus fuscomaculatus (Anura: Leptodactylidae) with a description of internal oral morphology. Zootaxa 370:1-8.

PEEL, M.C., FINLAYSON, B.L. \& MCMAHON, T.A. 2007. Updated world map of the Köppen-Geiger climate classification. Hydrol. Earth Syst. Sci. 11(5):1633-1644.

POMBAL Jr., J.P. \& GORDO, M. 2004. Anfíbios anuros da Juréia. In Estação Ecológica Juréia-Itatins: ambiente físico, flora e fauna (O.A.V. Marques \& W. Duleba, eds.). Editora Holos, Ribeirão Preto, p. 243-256.

POMBAL Jr., J.P. \& HADDAD, C.F.B. 1992. Espécies de Phyllomedusa do grupo burmeisteri do Brasil oriental, com descrição de uma espécie nova (Amphibia, Hylidae). Rev. Bras. Biol. 52(2):217-229.

POMBAL Jr., J.P. \& HADDAD, C.F.B. 2005. Estratégias e modos reprodutivos de anuros (Amphibia) em uma poça permanente na Serra de Paranapiacaba, sudeste do Brasil. Pap. Avul. Zool. 45(15):201-213.

POMBAL Jr., J.P., HADDAD, C.F.B. \& KASAHARA, S. 1995. A new species of Scinax (Anura: Hylidae) from southeastern Brazil, with comments on the genus. J. Herpetol. 29(1):1-6.

PRADO, C.P.A., UETANABARO, M. \& LOPES, F.S. 2000. Reproductive strategies of Leptodactylus chaquensis and L. podicipinus in the Pantanal, Brazil. J. Herpetol. 34(1):135-139. 
PRADO, C.P.A., UETANABARO, M. \& HADDAD, C.F.B. 2002. Description of a new reproductive mode in Leptodactylus (Anura, Leptodactylidae), with a review of the reproductive specialization toward terrestriality in the genus. Copeia 2002(4):1128-1133.

RIBEIRO JÚNIOR, J.W. \& BERTOLUCI, J. 2009. Anuros do cerrado da Estação Ecológica e da Floresta Estadual de Assis, sudeste do Brasil. Biota Neotrop. 9(1): http://www.biotaneotropica.org.br/v9n1/pt/abstrac t?inventory+bn02709012009 (último acesso em 31/08/2009).

RIBEIRO, M.C., METZGER, J.P., MARTENSEN, A.C., PONZONI, F.J. \& HIROTA, M.M. 2009. The Brazilian Atlantic Forest: how much is left, and how is the remaining forest distributed? Implications for conservation. Biol. Conserv. 142(6):1141-1153.

RODRIGUES, D.J., LOPES, F.S. \& UETANABARO, M. 2003. Padrão reprodutivo de Elachistocleis bicolor (Anura, Microhylidae) na Serra da Bodoquena, Mato Grosso do Sul, Brasil. Iheringia, Ser. Zool. 93(4):365-371.

RODRIGUES, D.J., UETANABARO, M. \& LOPES, F.S. 2005. Reproductive patterns of Trachycephalus venulosus (Laurenti, 1768) and Scinax fuscovarius (Lutz, 1925) from the Cerrado, Central Brazil. J. Nat. Hist. 39(35):3217-3226.

RODRIGUES, R.R., JOLY, C.A., BRITO, M.C.W, PAESE, A., METZGER, J.P., CASATTI, L., NALON, M.A., MENEZES, N., IVANAUSKAS, N.M.,BOLZANI, V. \& BONONI, V.L.R. 2008. Diretrizes para a conservação da biodiversidade no estado de São Paulo. Instituto de Botânica e FAPESP, São Paulo.

ROSSA-FERES, D.C., MARTINS, M., MARQUES, O.A.V., MARTINS, I.A., SAWAYA, R.J. \& HADDAD, C.F.B. 2008. Herpetofauna. In Diretrizes para a conservação e restauração da biodiversidade no Estado de São Paulo (R.R. Rodrigues \& et al., coords.). Instituto de Botânica e FAPESP, São Paulo, p. 83-94.

ROSSA-FERES, D.C. \& JIM, J. 1994. Distribuição sazonal em comunidades de anfíbios anuros na região de Botucatu, São Paulo. Rev. Brasil. Biol. 54(2):323-334.

ROSSA-FERES, D.C. \& JIM, J. 2001. Similaridade no sítio de vocalização em uma comunidade de anfíbios anuros na região noroeste do Estado de São Paulo, Brasil. Rev. Brasil. Zool. 18(2):439-454.

ROSSET, S.D. 2008. New species of Odontophrynus Reinhardt and Lütken 1862 (Anura: Neobatrachia) from Brazil and Uruguay. J. Herpetol. 42(1):134-144.

ROSSET, S.D., BALDO, D., LANZONE, C., \& BASSO, N. 2006. Review of the geographic Distribution of diploid and tetraploid populations of the Odontophrynus americanus species complex (Anura: Leptodactylidae). J. Herpetol. 40(4):465-477.

SÁ, R.O., DUBOIS, A. \& OHLER, A. 2007. Designation of a neotype for Leptodactylus gracilis (Duméril and Bibron, 1840) (Amphibia: Leptodactylidae). S. Am. J. Herpetol. 2(3):175-178.

SANTOS, A.J. 2003. Estimativas de riqueza em espécies. In Métodos de estudos em biologia da conservação e manejo da vida silvestre (L. Cullen Jr., R. Pudran \& C.Valladares-Pádua, eds.). Editora da UFPR, Curitiba, p. 19-41.

SANTOS, T.G., ROSSA-FERES, D.C. \& CASATTI, L. 2007. Diversidade e distribuição espaço-temporal de anuros em região com pronunciada estação seca do sudeste do Brasil. Iheringia, Ser. Zool. 97(1):37-49.

SANTOS, T.G. \& CECHIN, S.Z. 2008. Amphibia, Anura, Leptodactylidae, Leptodactylus chaquensis: distribution extension in the state of Rio Grande do Sul, Brazil. Check List 4(2):142-144.

SANTOS, T.G., VASCONCELOS, T.S., ROSSA-FERES, D.C. \& HADDAD, C.F.B. 2009. Anurans of a seasonally dry tropical forest: Morro do Diabo State Park, São Paulo state, Brazil. J. Nat. History 43(15-16):973-993.

SCOTT, N.J. \& WOODWARD, B.D. 1994. Standard techniques for inventory and monitoring: survey at breeding sites. In Measuring and monitoring biological diversity: standard methods for amphibians (W.R. Heyer, M.A. Donnelly, R.W. McDiarmid, L.A.C. Hayek \& M.S. Foster, eds.). Smithsonian Institution Press, Washington, p. 118-125.
SECRETARIA DO MEIO AMBIENTE DO ESTADO DE SÃO PAULO - SMA. 2009. Lista da fauna ameaçada de extinção no estado de São Paulo. São Paulo. http://www.ambiente.sp.gov.br/fauna.php (último acesso em 11/08/2009.)

STUART, S., HOFFMAN, M., CHANSON, J., COX, N., BERRIDGE, R., RAMANI, P. \& YOUNG, B. 2008. Threatened Amphibians of the World. Lynx Editions, Barcelona.

TABANEZ, M.F., DURIGAN, G., KEUROGHLIAN, A., BARBOSA, A.F., FREITAS, C.A., SILVA, C.E.F., SILVA, D.A., EATON, D.P., BRISOLLA, G., FARIA, H.H., MATTOS, I.F.A., LOBO, I.M.T., BARBOSA, M.R., ROSSI, M., SOUZA, M.G., MACHADO, R.B., PFEIFER, R.M., RAMOS, V.S., ANDRADE, W.J. \& CONTIERI, W.A. 2005. Plano de manejo da Estação Ecológica dos Caetetus. Ser. Reg. Inst. Florestal 29:1-103.

TOLEDO, L.F. \& HADDAD, C.F.B. 2005. Reproductive biology of Scinax fuscomarginatus (Anura, Hylidae) in south-eastern Brazil. J. Nat. Hist. 39(32):3029-3037.

TOLEDO, L.F., ZINA, J. \& HADDAD, C.F.B. 2003. Distribuição espacial e temporal de uma comunidade de anfíbios anuros do município de Rio Claro, São Paulo, Brasil. Holos Environment 3(2):136-149.

TOLEDO, L.F., CASTANHO, L.M. \& HADDAD, C.F.B. 2005. Recognition and distribution of Leptodactylus mystaceus (anura; leptodactylidae) in the state of São Paulo, southeastern Brazil. Biota Neotrop. 5(1): http:// www.biotaneotropica.org.br/v5n1/pt/abstract?article+BN00505012005 (último acesso em 10/08/2009).

VASCONCELOS, T.S. \& ROSSA-FERES, D.C. 2005. Diversidade, distribuição espacial e temporal de anfíbios anuros (Amphibia, Anura) na região noroeste do estado de São Paulo, Brasil. Biota Neotrop. 5(2): http:// www.biotaneotropica.org.br/v5n2/pt/abstract?article+BN01705022005 (último acesso em 10/08/2009).

VAZ-FERREIRA, R. \& GEHRAU, A. 1975. Comportamiento epimeletico de la rana comun, Leptodactylus ocellatus (L.) (Amphibia, Leptodactylidae). I. Atencion de la cria y actividades alimentarias y agresivas relacionados. Physis 34(1):1-14.

VELOSO, H.P., RANGEL FILHO, A.L. \& LIMA, J.C.A. 1991. Classificação da vegetação brasileira adaptada a um sistema universal. IBGE, Rio de Janeiro.

VIZOTTO, L.D. 1967. Desenvolvimento de anuros da região norte-ocidental do Estado de São Paulo. Tipografia Rio Preto, São José do Rio Preto.

WEYGOLDT, P. \& CARVALHO - SILVA, S.P. 1992. Mating and oviposition in the hylodine frog Crossodactylus gaudichaudii (Anura: Leptodactylidae). Amphibia-Reptilia 13(1):35-45.

WELLS, K.D. 1977. The social behavior of anuran amphibians. An. Behav. 25(3):667-693.

ZANK, C., KAEFER, I.L., COLOMBO, P., LINGNAU, R., SANTOS Jr., A.P.,BOTH, C., D'AGOSTINI, F.M., SANTOS, R.C. \& CECHIN, S.Z. 2008. Amphibia, Anura, Leptodactylidae, Leptodactylus furnarius: Rediscovery and distribution extension in the State of Rio Grande do Sul, Brazil. Check List 4(1):89-91.

ZINA, J. \& HADDAD, C.F.B. 2005. Reproductive activity and vocalizations of Leptodactylus labyrinthicus (Anura: Leptodactylidae) in southeastern Brazil. Biota Neotrop. 5(2): http://www.biotaneotropica.org.br/v5n2/pt/ abstract?article+BN00605022005 (último acesso em 10/08/2009).

ZINA, J., ENNSER, J., PINHEIRO, S.C.P., HADDAD, C.F.B. \& TOLEDO, L.F. 2007. Taxocenose de anuros de uma mata semidecídua do interior do Estado de São Paulo e comparações com outras taxocenoses do Estado, sudeste do Brasil. Biota Neotrop. 7(2): http://www.biotaneotropica. org.br/v7n2/pt/abstract?article+bn00607022007 (último acesso em 10/08/2009).

Recebido em 1/09/09 Versão reformulada recebida em 5/01/10 Publicado em 18/02/10 
Apêndice 1. Caracterização dos corpos d'água estudados na Estação Ecológica dos Caetetus (EEC). Todos os córregos amostrados são perenes e de mesmo porte $\left(2^{\mathrm{a}}\right.$ ordem $)$. $\mathrm{AT}=$ Açude Temporário; $\mathrm{AP}=$ Açude Permanente; $\mathrm{BT}=$ Brejo Temporário; $\mathrm{PT}=$ Poça Temporária; $\mathrm{AC}=\mathrm{Alagado}$ de Córrego $(\mathrm{Planície})$; $\mathrm{PB}=$ Poça temporária na Borda da mata; $\mathrm{RP}=$ Represa Permanente; $\mathrm{CA}=$ Córrego com fundo Arenoso; $\mathrm{CR}=$ Córrego com fundo Rochoso; $\mathrm{RB}=\mathrm{Represa}$ permanente na Borda. Legenda: VAR - vegetação arbórea; VAT - vegetação arbustiva do sub-bosque; VHR - vegetação herbácea rasteira (Poaceae); SN, solo nu. *Transecto de $100 \mathrm{~m}$.

Appendix 1. Characteristics of the water bodies sampled in Caetetus Ecological Station (EEC). All streams are permanent, second order streams. AT $=$ Temporary Pond; AP = Permanent Pond; BT = Temporary Swamp; PT = Temporary Puddle; AC = Swamp in Stream Border; $\mathrm{PB}=$ Temporary Puddle in Forest Edge; $\mathrm{RP}=$ Permanent Lake; CA = Stream with Sandy Bottom; CR = Stream with Rocky Bottom; RB = Permanent Lake in Forest Edge. Legenda: VAR - arboreal vegetation; VAT - understore arbustive vegetation; VHR - herbaceous vegetation (Poaceae); SN, naked soil. *Transect (100 m).

\begin{tabular}{|c|c|c|c|c|c|}
\hline Corpo d'água & Localização geográfica & Altitude(m) & Fisionomia do entorno & Área $\left(\mathbf{m}^{2}\right)$ & Vegetação de entorno \\
\hline AT & $22^{\circ} 22^{\prime} 49^{\prime \prime} \mathrm{S}$ e $49^{\circ} 40^{\prime} 20^{\prime \prime} \mathrm{W}$ & 666 & Pasto vizinho a EEC & 530 & VHR, SN \\
\hline $\mathrm{AP}$ & $22^{\circ} 23^{\prime} 18^{\prime \prime} \mathrm{S}$ e $49^{\circ} 40^{\prime} 31^{\prime \prime} \mathrm{W}$ & 662 & Pasto vizinho a EEC & 360 & VHR, SN \\
\hline BT & $22^{\circ} 24^{\prime} 38^{\prime \prime} \mathrm{S}$ e $49^{\circ} 41^{\prime} 37^{\prime \prime} \mathrm{W}$ & 513 & Clareira na área nuclear da EEC & 250 & VAR, VAT \\
\hline $\mathrm{BP}$ & $22^{\circ} 24^{\prime} 40^{\prime \prime} \mathrm{S}$ e $49^{\circ} 41^{\prime} 35^{\prime \prime} \mathrm{W}$ & 513 & Clareira na área nuclear da EEC & 340 & VAR, VAT \\
\hline PT1 & $22^{\circ} 24^{\prime} 36^{\prime \prime} \mathrm{S}$ e $49^{\circ} 41^{\prime} 35^{\prime \prime} \mathrm{W}$ & 514 & Área nuclear da EEC & 120 & VAR, VAT \\
\hline PT2 & $22^{\circ} 24^{\prime} 37^{\prime \prime} \mathrm{S}$ e $49^{\circ} 41^{\prime} 36^{\prime \prime} \mathrm{W}$ & 514 & Área nuclear da EEC & 35 & VAR, VAT \\
\hline PT3 & $22^{\circ} 24^{\prime} 37^{\prime \prime} \mathrm{S}$ e $49^{\circ} 41^{\prime} 37^{\prime \prime} \mathrm{W}$ & 513 & Área nuclear da EEC & 8 & VAR, VAT \\
\hline PT4 & $22^{\circ} 22^{\prime} 45^{\prime \prime} \mathrm{S}$ e $49^{\circ} 40^{\prime} 47^{\prime \prime} \mathrm{W}$ & 650 & Área nuclear da EEC & 25 & VAR, VAT \\
\hline $\mathrm{AC}$ & $22^{\circ} 24^{\prime} 47^{\prime \prime} \mathrm{S}$ e $49^{\circ} 40^{\prime} 59^{\prime \prime} \mathrm{W}$ & 537 & Área aberta no interior da EEC & $>1000$ & VAR, VAT \\
\hline PB & $22^{\circ} 25^{\prime} 05^{\prime \prime} \mathrm{S}$ e $49^{\circ} 43^{\prime} 07^{\prime \prime} \mathrm{W}$ & 551 & Área de entorno na borda da EEC & 280 & VAR, VHR \\
\hline $\mathrm{RP}$ & $22^{\circ} 22^{\prime} 44^{\prime \prime} \mathrm{S}$ e $49^{\circ} 40^{\prime} 47^{\prime \prime} \mathrm{W}$ & 648 & Clareira no interior da EEC & 610 & VAR, VAT \\
\hline $\mathrm{CA}$ & $22^{\circ} 24^{\prime} 39^{\prime \prime} \mathrm{S}$ e $49^{\circ} 41^{\prime} 36^{\prime \prime} \mathrm{W}$ & 512 & Área nuclear da EEC & $*$ & VAR, VAT \\
\hline $\mathrm{CR}$ & $22^{\circ} 23^{\prime} 27^{\prime \prime} \mathrm{S}$ e $49^{\circ} 41^{\prime} 31^{\prime \prime} \mathrm{W}$ & 554 & Área nuclear da EEC & $*$ & VAR, VAT \\
\hline RB1 & $22^{\circ} 24^{\prime} 10^{\prime \prime} \mathrm{S}$ e $49^{\circ} 40^{\prime} 31^{\prime \prime} \mathrm{W}$ & 618 & Área de entorno na borda da EEC & 950 & VHR \\
\hline RB2 & $22^{\circ} 23^{\prime} 15^{\prime \prime} \mathrm{S}$ e $49^{\circ} 43^{\prime} 33^{\prime \prime} \mathrm{W}$ & 634 & Área de entorno na borda da EEC & $>1000$ & VAR, VAT, SN \\
\hline
\end{tabular}

Apêndice 2. Anfíbios anuros coletados na Estação Ecológica dos Caetetus (EEC) (Gália, SP) e depositados nas coleções VESALQ - Laboratório de Zoologia de Vertebrados, Departamento de Ciências Biológicas, Escola Superior de Agricultura “Luiz de Queiroz”, Universidade de São Paulo, Piracicaba, São Paulo (numeração de campo) - e DZSJRP - Amphibia-adults, Departamento de Zoologia e Botânica, Instituto de Biociências, Letras e Ciências Exatas, Universidade Estadual Paulista, São José do Rio Preto, São Paulo.

Appendix 2. Anuran amphibians colected in Caetetus Ecological Station (EEC) (Gália, SP) and deposited in the following herpetological collections: VESALQ - Laboratório de Zoologia de Vertebrados, Departamento de Ciências Biológicas, Escola Superior de Agricultura "Luiz de Queiroz", Universidade de São Paulo, Piracicaba, São Paulo (field numbers); and DZSJRP - Amphibia-adults, Departamento de Zoologia e Botânica, Instituto de Biociências, Letras e Ciências Exatas, Universidade Estadual Paulista, São José do Rio Preto, São Paulo.

Rhinella ornata (DZSJRP 13620-13678, VESALQ EEC010, 025, 035), Rhinella schneideri (VESALQ EEC004), Vitreorana uranoscopa (VESALQ EEC037), Haddadus binotatus (DZSJRP 13679-13683, VESALQ EEC019), Odontophrynus americanus (DZSJRP 13684-13686, VESALQ EEC016, 018), Dendropsophus elianeae (DZSJRP 13687), Dendropsophus minutus (VESALQ EEC012, 028), Dendropsophus nanus (DZSJRP 13688, VESALQ EEC008), Hypsiboas albopunctatus (VESALQ EEC007), Hypsiboas caingua (VESALQ EEC026), Hypsiboas faber (VESALQ EEC005, 029, 032, 042), Hypsiboas lundii (VESALQ EEC006), Itapotihyla langsdorffi (VESALQ EEC013), Phyllomedusa tetraploidea (VESALQ EEC039), Scinax fuscomarginatus (DZSJRP 13689-13690), Scinax fuscovarius (VESALQ EEC017), Scinax hiemalis (VESALQ EEC041, 043), Scinax perereca (VESALQ EEC002), Scinax rizibilis (VESALQ EEC003, 015, 027), Crossodactylus cf. caramaschii (DZSJRP 13691-13693, VESALQ EEC023, 033), Eupemphix nattereri (DZSJRP 13694, VESALQ EEC009), Physalaemus cuvieri (DZSJRP 13695-13717, VESALQ EEC011, 021, 022, 031), Physalaemus marmoratus (DZSJRP 13718-13719), Physalaemus cf. olfersii (DZSJRP 13720, VESALQ EEC014), Leptodactylus chaquensis (VESALQ EEC040), Leptodactylus cf. furnarius (DZSJRP 13721), Leptodactylus fuscus (VESALQ EEC034), Leptodactylus labyrinthicus (VESALQ EEC020), Leptodactylus cf. latrans (VESALQ EEC038) Leptodactylus mystaceus (DZSJRP 13722-13728, VESALQ EEC001), Leptodactylus mystacinus (DZSJRP 13729-13730, VESALQ EEC030), Elachistocleis cf. ovalis (VESALQ EEC024, 036). 